


\title{
Intraosseous heat generation during guided osteotomy for dental implantological purposes
}

\author{
PhD thesis
}

by

Adam Ibrahim Barrak, DMD

Department of Oral and Maxillofacial Surgery

University of Szeged

Supervisor:

József Piffkó, MD, DMD, PhD, full professor

Doctoral School of Clinical Medicine

University of Szeged

Szeged, 2018 
Publications providing the basis of the thesis

I. Effect of the Combination of Low-Speed Drilling and Cooled Irrigation Fluid on Intraosseous Heat Generation During Guided Surgical Implant Site Preparation: An In Vitro Study.

Barrak I, Joób-Fancsaly A, Varga E, Boa K, Piffko J.

Implant Dentistry, 2017; 26(4):541-546.

article type: original article

DOI: 10.1097/ID.0000000000000607.

PMID: 28542041

$\mathrm{IF}_{2017}: 1.307$

II. Intraosseous Heat Generation During Osteotomy Performed Freehand and Through Template With an Integrated Metal Guide Sleeve: An In Vitro Study. Barrak I, Joób-Fancsaly Á, Braunitzer G, Varga E Jr, Boa K, Piffkó J.

Implant Dentistry, 2018; 27(3):342-350.

article type: original article

DOI: 10.1097/ID.0000000000000763.

PMID: 29762185

$\mathrm{IF}_{2017}: 1.307$

\section{Other publications}

Intraosseous generation of heat during guided surgical drilling: an ex vivo study of the effect of the temperature of the irrigating fluid

Boa K, Barrak I, Varga E Jr, Joob-Fancsaly A, Varga E, Piffko J

British Journal of Oral \& Maxillofacial Surgery, 2016; 54(8):904-908.

article type: original article

DOI: $10.1016 /$ j.bjoms.2016.06.004

PMID: 27371340

$\mathrm{IF}_{2016}: 1.218$

Comparison of effects of different fluoride containing prophylactics on the growth of Streptococcus mutans on titanium surfaces - an in vitro study

Barrak I, Urban E, Turzo K, Stajer A

Fogorvosi szemle 2017 March; 110(1):20-24

PMID: 29847064

IF: N/A

Navigation in implantology: Accuracy assessment regarding the literature

Barrak I, Varga E, Piffko J

Fogorvosi szemle 2016 June; 109(2):61-8

PMID: 27544966

IF: N/A 
Short- and Long-Term Influence of Fluoride-Containing Prophylactics on the Growth of Streptococcus mutans on Titanium Surface

Barrak I, Urbán E, Turzó K, Nagy K, Braunitzer G, Stájer A

Implant Dentistry, 2015 Dec; 24(6):675-9.

article type: original article

DOI: $10.1097 / \mathrm{ID} .0000000000000294$

PMID: 26134690

$\mathrm{IF}_{2015}: 1.023$

Heat generation during guided and freehand implant site preparation at drilling speeds of 1500 and 2000 RPM: an in vitro study

Barrak I, Boa K, Joob-Fancsaly A, Sculean A, Piffko J

Accepted for publication with revisions in Oral Health and Preventive Dentistry article type: original article

\section{Scientometry}

Cumulative IF of publications providing the basis of the thesis:

Cumulative IF of all publications (as of October 2018):

Number of independent citations: 


\section{Abbreviations}

ANOVA

CBCT

CT

HU

RPM

TiN

SEM

OPG

RANKL

Tukey's HSD: analysis of variance

cone-beam computed tomography

computed tomography

Hounsfield units

revolutions per minute

Titanium Nitride

scanning electron microscopy

osteoprotegerin

receptor activator of $\mathrm{NF}-\kappa \mathrm{B}$ ligand

test of honestly significant difference according to John Tukey 


\section{Table of contents}

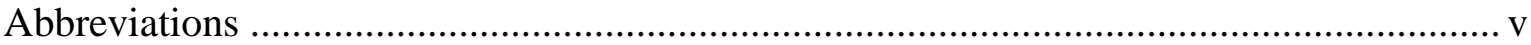

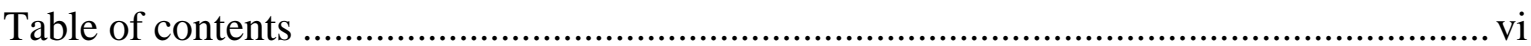

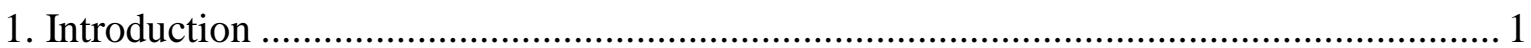

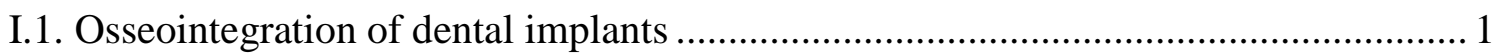

I.2. Thermal osteonecrosis, thermal damage …........................................................ 2

I.3 Bone models and methods used to measure heat generation .................................... 3

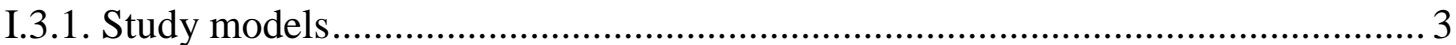

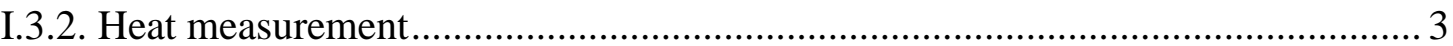

I.4. Parameters that influence intraosseous temperature rise during osteotomy ................ 3

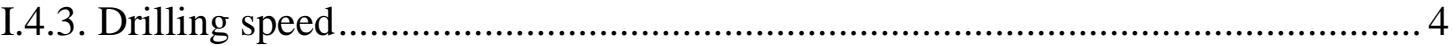

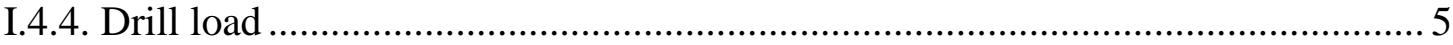

I.4.5. Drilling time

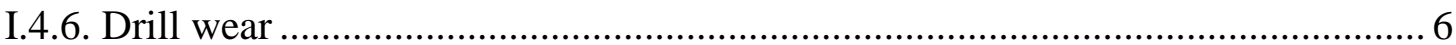

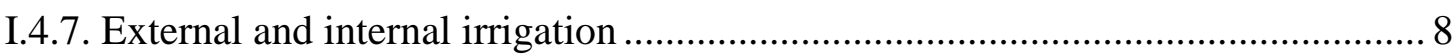

I.5. The guided approach to oral implantology ..........................................................

I.5.1. Intraosseous temperature in guided osteotomy ................................................ 11

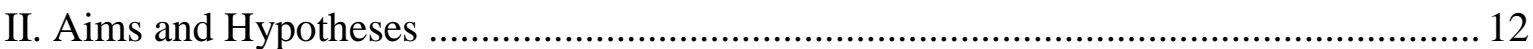

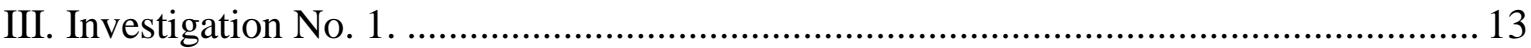

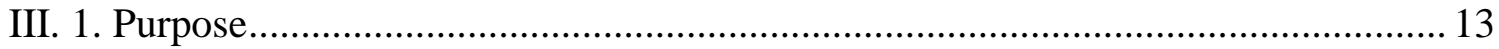

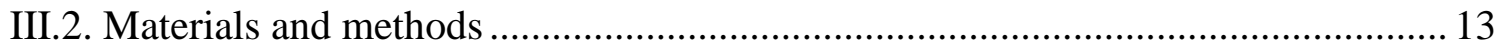

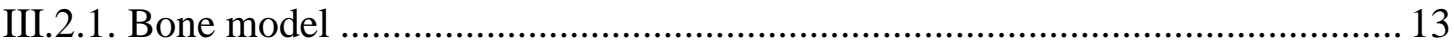

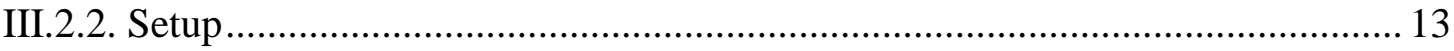

III.2.3. Collection of data and statistical analysis .................................................. 17

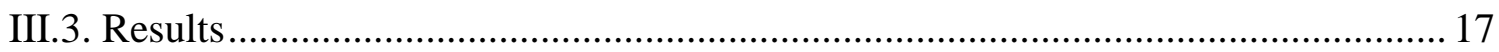

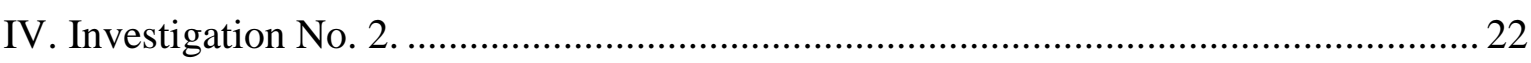

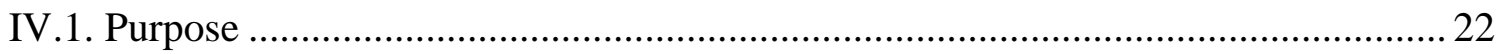


IV.2. Materials and methods.

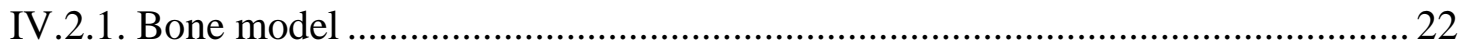

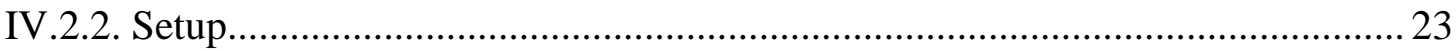

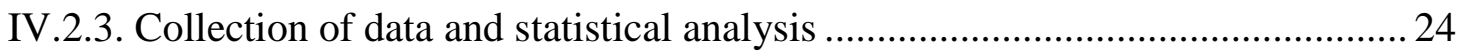

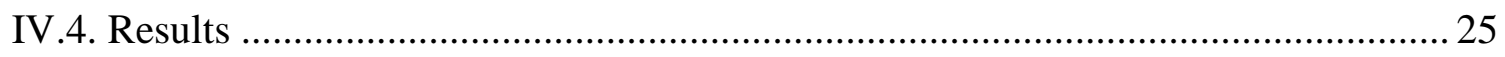

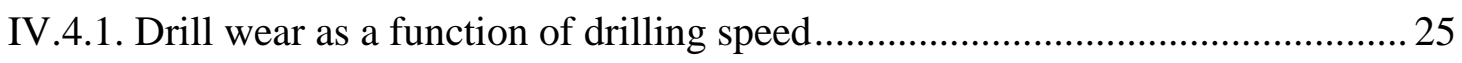

IV.4.2. The effect of the individual factors on temperature elevation ......................... 26

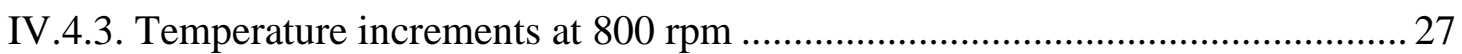

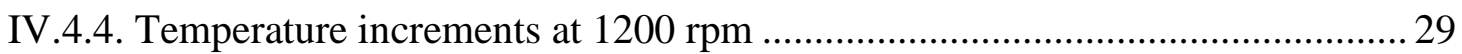

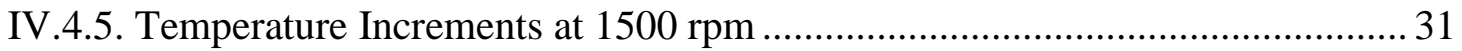

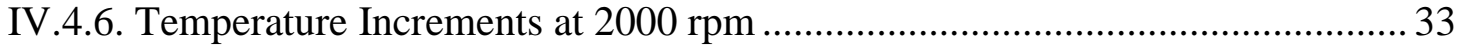

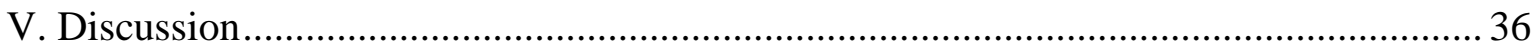

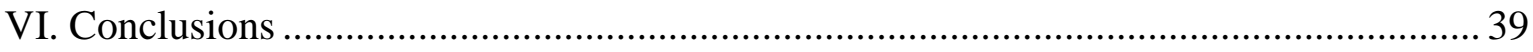

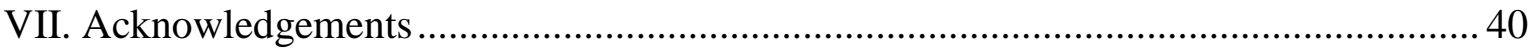

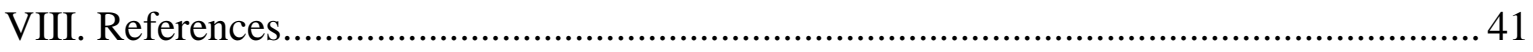

Appendix: Copies of the publications that provide the basis of the thesis ......................... 52 


\section{Introduction}

Prosthodontically driven implant surgery has been subject of interest to dental professionals for the past decade. The correct positioning of implants has a number of obvious advantages, such as favourable functional and aesthetic outcomes, better occlusion and less chance of implant overload, to mention just a few. A well-positioned implant can also make it easier for the patient to maintain good oral hygiene, once the superstructure has been inserted. What follows is profound description of the procedure of implant surgery, with special attention to the guided surgical approach $(1,2)$.

\section{I.1. Osseointegration of dental implants}

Osseointegration, the research of which was pioneered by the Swedish Per- Ingvar Brånemark from the 1960s on, has become one of the most extensively researched phenomena in clinical dentistry(3).

The success of medical interventions based on osseointegration depends on a torough understanding of the reparative properties of hard and soft tissues. The goal of the dental professional is to achieve a predictable and functional tissue response through the placement of tooth root analogues(4).

In the early 1960s Brånemark found that titanium chambers of screw-shaped design, implanted in bone, could not be removed from adjacent bone once they healed in, which was the first experimental proof of osseointegration. Brånemark concluded that the edentulous jaw could be provided with jaw bone-anchored prostheses according to the principle of osseointegration with excellent and predictable long-term prognosis $(5,6)$.

In order to allow osseointegration, the preparation of the bone must be performed in a minimally invasive way to avoid excessive injury of both the soft and hard tissues. Brånemark et al. concluded that a minimal amount of bone in the edentulous jaw should be removed and that the basic topography should remain the same. The retention of the provisional denture should be maintained during the healing of the implants. Brånemark also suggested that for the rehabilitation of completely edentulous cases, screw-shaped implants made of pure titanium, $10 \mathrm{~mm}$ long and $3.7 \mathrm{~mm}$ in diameter would be optimal (7). The titanium fixture did not seem to cause any adverse effect, and bone resorption from disuse atrophy was reduced as well. As for the healing time, Brånemark found that it was between 3 to 6 months, depending mostly on the healing potential of the given jaw bone of 
the individual patient (8). When connected to abutments, the bone around the implants remodels over a period of $\geq 1$ year until it reaches a so-called steady state Installation surgical trauma and adaptation to the masticatory force also contributes to marginal bone loss, which is an otherwise normal concomitant phenomenon of dental implantation. Furthermore, Brånemark pointed out that successful osseointegration necessitated extremely careful management, both in the surgical and prosthodontic sense $(4,9)$. Longterm biochemical and biophysical analyses indicated that there was an active interaction between the implanted titanium fixture and the soft and hard tissues, which eventually led to an improved anchorage $(3,4,8,10-12)$. Therefore, it has become widely accepted that osseointegration, defined as direct bony support to the implant body, is the most stable means of implant anchorage. However, there are various factors that can influence this process. This thesis will focus on one of the most important of those factors: heat generated during implant site preparation.

\section{I.2. Thermal osteonecrosis, thermal damage}

As the application of metal implants has become routine in musculoskeletal trauma surgery, orthopaedic surgery, spine surgery, cranio-maxillofacial surgery, dentistry and oral implantology, drilling of bone has also become one of the most common basic surgical steps. Bone tissue is one of the most highly cellular and most richly vascularized structures in the human body. Previous studies have demonstrated that healing of the osseous structure can occur via repair or regeneration (13-15). As for the process of repair, this can be influenced by several factors including implant design, chemical composition, the material and shape of the implant, the physiological characteristics of the host bone bed, loading conditions, the topography of the implant surface, the healing potential of the host bone, the use of adjuvant treatments, pharmacological agents and also heat generation during osteotomy $(14,16-22)$. The bone tissue is very vulnerable to thermal injury, and the temperature threshold for tissue survival during osteotomy is $47^{\circ} \mathrm{C}$ when drilling is maintained for more than 1 minute (23-25). Therefore, it is critical for successful osseointegration to keep heat generation under control during osteotomy. Excess heating above this limit can lead to the primary failure to of osseointegration. Frictional heat generated during the time of surgery will always cause a certain degree of necrosis of the surrounding undifferentiated and differentiated cells, therefore it represents a significant risk for failed bone integration. In vitro studies have found that heat generation during a session of osteotomy depends on multiple factors, as discussed below $(22,26)$. 


\section{I.3 Bone models and methods used to measure heat generation}

\section{I.3.1. Study models}

There is no standard model for the observations into the preparation of implant sites. A variety of different osseous models have been used based on bone blocks from pig rib (22), pig mandible and maxilla (27), sheep tibia (28), bovine cortical/medullary bone (29-37), rabbit tibia (38) and rabbit mandible $(39,40)$. There were studies which used synthetic blocks or resin models (41-44).

\section{I.3.2. Heat measurement}

Different methods have been used to observe the heat generated during drilling of bone during the dental implant placement. To the extent of our knowledge, currently only 2 methods have been described throughout the literature, used to record heat generated in real time. Thermocouples, which allow direct measurement $(43,45-51)$, this method was first presented in the field of oral implantology by Keiditsch and Horch (52).

The other option for heat measurement is the infrared thermography which provides an indirect estimate $(42,48,53,54)$.

Studies on the use of the well-established thermocouple technology are still not uniform. There are variations of the distance to the final drilling path and the depth of the vertical dimensions. A further problem is the limited ability to detect spot temperatures (26). The latter mentioned disadvantage can be avoided by the use of infrared technology, which is described to be more accurate (53).

\section{I.4. Parameters that influence intraosseous temperature rise during osteotomy}

\section{I.4.1. Diameter of the drill}

It has been proved in 3 studies by Strbac and his colleagues that the thermal increment is inversely proportional to the diameter of the drilling burs $(41,55,56)$. During the investigations they used a real-time model with 14 temperature sensors at defined depths with predefined distances of 1 and $2 \mathrm{~mm}$ from the final drilling path (41,55). During drilling the $2 \mathrm{~mm}$ diameter twist drill was reached higher temperatures than the $3.5 \mathrm{~mm}$ diameter conical implant drills with the use of coolant. In their further investigations Strbac et al. observed that the first $2 \mathrm{~mm}$ diameter twist drill, which was used before the other diameters $(3.5,4.3,5.0)$, caused significantly higher temperatures than sequential drills 
with conical drill bits (41). Augustin and his colleagues from different part of the medical field (orthopaedic, traumatology) have observed the effect of drill diameter on the temperature generated during drilling as well (57). Augustin et al. reported that with the increase in drill diameter the contact surface between the drill and the bone increases, therefore this phenomenon leads to an increase in the overall friction which results in a higher heat generated.

\section{I.4.2. Design of the drill and number of blades}

The shape of the implant placed already determines the shape of the drill usually. Furthermore, a relationship can be observed between the temperature at the cutting site and drilling time and the design of the drills or burs. During the rotary cutting of the cortical layer of the bone, it took more time to cut with the spiral drill with its two spiral blades therefore a larger amount of heat was generated from the tip of the bur during the drilling. The round bur, which has eight blades completed the drilling in a shorter period of time (22). Having an extra flute in the drill design may influence the cutting efficiency in a positive way (42). On the contrary, it is also worth keeping in mind that the additional flutes may narrow the channels of the flutes that would otherwise function as a path for the removal of the bone chips, and this might eventually result in elevated frictional heat and further impaired cutting efficiency. More research needs to be conducted concerning the optimal number of flutes and its effect on cutting efficiency and frictional heat generation (42). It has already been recommended by Jacobsson and his colleagues that a graded series of drill sizes should be used instead of one large drill (58). Sharawy and his group suggested that continued drilling before allowing the temperature to return to the baseline level might lead to further temperature elevation, which can gradually reach a clinically concerning level. The usual 2 to 5 re-entries in the osteotomy hole during sequential drilling may further increase heat generation during rotary cutting. Therefore, the authors concluded that the surgeon should interrupt the drilling procedure every $5 \mathrm{~s}$ for at least $10 \mathrm{~s}$ and apply irrigation fluid to the bone, which will significantly decrease the time that the bone is exposed to elevated temperatures (27).

\section{I.4.3. Drilling speed}

Thompson (59) investigated thermal changes, mechanical effects and initial histologic responses to drilling in bone at various speeds in the range of 125 to $2,000 \mathrm{rpm}$. No coolant was used during his observations and within the above-mentioned range, the temperature 
increased from $38.3{ }^{\circ} \mathrm{C}$ to $65.5{ }^{\circ} \mathrm{C}$ during the increase of the drilling speed. This was confirmed by Pallan (60). Hirsch and Matthews (61) found a directly proportional relationship between heat production and drilling speed when comparing speed ranges from $345 \mathrm{rpm}$ to 2,900 rpm. Wedgwood and Lavelle (62) reported growing heat production with increasing rotational speeds up to an rpm of 350. Eriksson and his colleagues $(63,64)$ proposed that the drilling speeds should remain in the range of 1,000-2,000 rpm. However, Eriksson did not experimentally investigate the temperature at drilling speeds greater than 2,000 rpm during the use of water-coolant. In their study, Iyer et al. $(39,40)$ found an inverse relationship between drill speed and heat production when coolant was used while performing the drilling procedures. Kim et al.(54) used infrared thermography to compare the temperature elevations during the use of a low-speed system (50 rpm) and 2 conventional systems (1200 rpm). The lowest and highest increases in temperature were $1.57{ }^{\circ} \mathrm{C}$ and $2.46{ }^{\circ} \mathrm{C}$ for conventional drilling and about $1.67{ }^{\circ} \mathrm{C}$ and $1.72{ }^{\circ} \mathrm{C}$ for the low speed drilling. The difference shown was not significant, and the bone was not over-heated at $50 \mathrm{rpm}$ without irrigation.

\section{I.4.4. Drill load}

Drill speed was not the only significant determinant of heat production. Rather, it was drilling force that was related to both the maximum temperature rise and the mean elevation during the entire drilling period (61). Increasing both the speed and the load allows the drill to cut more efficiently than at slower speeds, thus generating less frictional heat. This pattern was observed by Brisman and colleagues (35) when they compared axial loads of 1.2 and $2.4 \mathrm{~kg}$ at 1,200 and 2,400 rpm. They found that the least heat was generated under $2.4 \mathrm{~kg}$ force with 2,400 rpm. Several authors investigated the heat generated at different loads when using a conventional drill $(65,66)$. Hobkirk and Rusiniak (67) demonstrated that the average force applied on the handpiece during implant site preparation is $1.2 \mathrm{~kg}$, but they did not investigate its role on heat generation. Majzoub and Cordioli (33) concluded that a drilling force of $2 \mathrm{~kg}$ remains in the clinical range. Rashad et al. (68) showed that increasing the axial load $(5,8,15$ and $20 \mathrm{~N})$ had no effect on heat production during conventional drilling in cancellous and cortical bone. Stelzle focused on how load affected the heat produced in hard tissue. Heat generated by a spiral bur, a trephine bur, and a piezoelectric instrument was compared at various loads between 0 and $1000 \mathrm{~g}$ (69). The temperature increment followed the pressure increase when using the piezoelectric instrument and the trephine bur, but with conventional drills the temperature started to drop 
at $500 \mathrm{~g}$. The maximum temperature using a conventional drill at a load of 400-500g was about $45.5{ }^{\circ} \mathrm{C}$; for trephine burs it was $43.9^{\circ} \mathrm{C}$ at a load of $9000-1000 \mathrm{~g}$, and for the piezosurgery it was $48.6^{\circ} \mathrm{C}$. To avoid thermal damage during preparation of the implant site, they proposed a maximum load of 100-400 g for piezosurgery, 100-200 g and 500$1000 \mathrm{~g}$ for the spiral drill, and 100-600 $\mathrm{g}$ for the trephine bur.

\section{I.4.5. Drilling time}

Heat generation is directly proportional to the duration of drilling and depends on various factors.(33) Kim et al concluded that at lower speeds drilling takes longer but does not lead to the increase of heat generated(54). Stelzle et al. (69) evaluated the applied load in 3 systems (piezosurgery, spiral bur, trephine bur) and found that the time required to prepare the cavity in the bone continuously decreased with the load. The least time was observed with the spiral bur (5.9 seconds) which was followed by the trephine bur ( 7.3 seconds); piezosurgery took 19.5 seconds. The elevation of temperature does seem to correlate with the drilling time. At maximum load, the lowest temperature measured was with the spiral bur $\left(40.3{ }^{\circ} \mathrm{C}\right)$, with the trephine bur this value was $43.9^{\circ} \mathrm{C}$ which was followed by $48.6^{\circ}$ Cduring the use of piezoelectric surgery. Rashad et al. have describe a similar outcome during their investigations.(68)

\section{I.4.6. Drill wear}

Drill wear is common phenomenon during drilling. At present many implant companies do not indicate how many times a drill bit should be used, thereby hindering the ability for dental professionals to understand the optimal frequency of drill replacement.(14) This could result in greater tissue trauma to the surgical bed, leading to higher rates of implant loss (70). The study conducted by Matthews and Hirsch (61) suggests that during bone drilling, bone temperature increases with the multiple use of drill. The repeated use of drill causes the cutting edges to wear out due to thermal and mechanical load encountered by them during the rotary cutting of the bone. The sharpness of the bur is directly related to the number of times used, pressure applied, sterilisation technique, construction material and surface treatment. Wear increases the surface roughness of cutting lips which increases the axial thrust force, temperature and cutting vibrations. Through the use of scanning electron microscopy (SEM) or light microscopy the wear of the drill bits can be detected and qualitative analysis of bony healing has been done immunohistochemically $(36,38,70$ 77). 
Allan et al (78) investigated the effect of drill wear on temperature rise during drilling of the porcine mandibles in vitro. They examined three different types of drill bits: one was new (Leibinger $1.5 \mathrm{~mm}$ diameter with two flutes), one was which had drilled 600 holes, and the third one had been in use for several months. They detected a significant difference in temperatures generated by the three drills and reported that the change in temperature elevation was due to the amount of wear.

Chacon et al (34) measured heat generated in bone by 3 implant drill systems after repeated drilling and sterilization procedures. They measured the temperature change with thermocouple in vitro using bovine femoral cortical bone specimen. Their results showed that the temperature increased with multiple usage of the drill bits. Harris and Kohles (79)in their study observed that repeated autoclave sterilization cycles cause a reduction in the cutting power of the drill bits. The investigation performed by Jochum and Reichart (80) using 20 Timedur cannon drills (ZL-Duraplant-Implant-4System) for 51 times in vitro on pig mandibles concluded that drilling of more than 40 times causes significant wear and an increase in temperature. However, no statistically significant difference was observed in bone heating between drills that were reused after washing and sterilization and drills that were used after washing only. They also suggested that blunting of the drill edge can be altered with disinfectant use and autoclaving.

Ercoli et al (70) investigated on bovine rib and found that the TiN-coated drills showed greater wear and significantly lower material removal rates as compared to non-coated drills. Misir et al. (45) measured increase in temperature of $4{ }^{\circ} \mathrm{C}$ and $10^{\circ} \mathrm{C}$ with $\mathrm{K}$ type thermocouple in vitro using the bovine femoral cortical bone specimen at a constant drill load of $2.0 \mathrm{~kg}$ with a speed of $1500 \mathrm{rpm}$ after 35 and 45 times of use respectively. Karaca et al. (81) performed studies on the protective coatings that have been applied to the drills with the intention of improving the durability of the drills. They concluded that TiN coated drill bits generate more temperature during rotary cutting in comparison to the drills without coating. Recently Oliveira et al (72) conducted drilling experiments on bovine bone with twisted stainless steel and ceramic drills to find out the relation between the thermal changes and drill wear. They found a positive correlation between temperatures generated and the number of drill usage. They also reported that no severe deformations or blunting was observed even after 50 uses. In his study Scarano (71) reported on higher temperatures with more use. They concluded that regarding repeated usage, SEM examinations revealed that even a number of 12 drilling procedures can result in a degradation of the cutting 
surface of trephine bur drills. Investigations on bony healing in rabbit tibias found no association between the number of times a drill was used and bony healing. A physiological balance of OPG (osteoprotegerin) and RANKL (receptor activator of the NF- $\kappa$ B ligand) was given in up to 50 drilling. Later, higher immunolabelling of all proteins was measured and there was a proportional relation between the expression of caspase 3 and the number of times a drill was used $(24,73,74)$.

The above discussion of past studies on drill wear suggests that the drill wear and temperature generated during bone drilling increases with the number of times a drill bit is re-used. However, no clear suggestion has been made on how many times a drill can be used until it starts producing a significant additional heat.

\section{I.4.7. External and internal irrigation}

The real relevance of the control of intraosseous temperature rise and the avoidance of thermal osteonecrosis during implant bed preparation lies in its effect on the possible histological changes at the implant-bone interface,that might indicate the impairment of the process of osseointegration (82). However, most of the available literature concentrates on the elucidation of the numerous aspects and parameters that might influence the intrabony temperature, and only a few studies have been investigating the link between irrigation and temperature on the histological changes at the implant site (83).

Extensive irrigation is a major influencing in the prevention of high temperatures at the bone interface $(22,32,61,70)$. Cooling can be internal or external, and the simultaneous use and the volume or temperature of the solution can vary.

Watanabe (22) conducted studies during heat generation in the presence or absence of irrigating fluid when drilling with IMZ, Brånemark, and ITI implant (F type) drills. He observed that maximum heat generated without irrigation was higher that with irrigation for any IMZ drill, and with irrigation, almost no heat was generated. Sener et al.(84) in their in vitro study concluded that more heat was generated in the superficial part of the cavity drilled than at the deeper parts. Therefore, external irrigation at room temperature proved to provide sufficient cooling during drilling. Lower temperature saline was more effective in cooling the osseous structure, and irrigation should be continued during the whole drilling process. 
Benington (85) and his group did a study on bovine bone, to compare the temperatures that were generated with external and internal irrigation systems while preparing implant sites. Statistically, no significant difference was observed for one irrigant system over the other. The clinical benefit of using more expensive internal irrigation systems is therefore deemed unjustifiable, on the grounds that these systems do not appear to reduce thermal challenge to the bone over and above that of simple flood irrigation. The beneficial influencing role of external drill cooling is now generally accepted and well-documented in the literature of dental implants $(86,87)$.

Internally cooled drills were introduce to implant dentistry in 1975 by the authors Meyer and Kirschner (88). The coolant is discharged from the tip of the drill, therefore it is hypothesised that cooling and rinsing effect of these drills would be better than with external cooled drills $(62,89-91)$. The above mentioned two authors (88) compared internal irrigation with no irrigation at drilling speeds of 1,300 and 2,000 rpm, they reported that although there was no difference in heat generation between different rotational speeds, an intrabony temperature of $25-35{ }^{\circ} \mathrm{C}$ with internal irrigation reached $103^{\circ} \mathrm{C}$ without it, justifying the important role of internal irrigation. Wedgwood and Lavelle (62) measured the temperature when using semi-elliptical and round burs with internal irrigation, external irrigation or no irrigation. High temperature elevation developed in all cases without irrigation and minimal heat developed when using internal irrigation.

\section{I.5. The guided approach to oral implantology}

Technological advances often influence the approach to implant therapy. In the last few years a rapid development could be observed in the field of computer-assisted implant placement. Increased beneficial use of computers was made possible through the recent advances in computer technology, which allowed the planning and the execution of various steps involved in dental reconstructions during the placement of dental implants. The above mentioned novel possibilities include computer assistance for the planning of surgical interventions, for the implementation of the surgical steps, for capturing intraoral situation and also for designing temporary and final prosthetic solutions or even for the manufacturing of prosthetic components $(92,93)$.

Cone-beam computed tomography (CBCT) scanning as a three-dimensional (3D) imaging tool led to a breakthrough in the field of implant dentistry, mainly because these scanning devices allow lower radiation dosages compared with the conventional computed 
tomography (CT) scanners (93-97). Combining the CBCT images with an implant planning software has made it possible to virtually plan the optimal implant positions, in regard of the future prosthetic needs and the vital anatomical structures. This information can be used to fabricate a drill guide, which ultimately results in the transfer of the planned implant position from the computer to the patient, with the guide directing both the osteotomy and the insertion of the implant (98). Most importantly, every step of the process can be performed in such a way that the predicted prosthodontically ideal implant position can be achieved without damaging the neighbouring anatomical structures (1).

The various guide systems include the planning of the implant positions, using software tools. The planned positions are converted into surgical guides or loaded further into a positioning software through a variety of different methods. Jung and his coworkers were the first to categorize many of these into dynamic and static systems (2). The dynamic systems incorporate surgical navigation and computer-aided navigation technologies, which allows the surgeon to change the surgical procedure and alter the implant position in real time using the anatomical information available from the preoperative CBCT or CT scan. Dynamic systems communicate the selected positions of the implants to the operative field with visual imaging tools on a monitor of a computer. The surgeon can see an avatar of the drill in a 3D relationship to the patient's previously scanned anatomy while preparing the implant site, therefore modifications can be made immediately with significantly more information. In addition, the navigation approach provides an essential benefit with a virtual surgical guidance that can be altered according to the conditions encountered during the surgery. Meanwhile, static systems are those that transfer the predetermined implant sites using rigid intraoral guides or surgical templates in the operating field (1).

Jung et al. in their systematic review concluded that the static systems have the tendency to be more precise than the dynamic approaches (2).

For the computer guided static surgery, different modalities can be distinguished regarding the procedure of the drill guide fabrication, such as stereolithography or the use of mechanical positioning devices which convert the radiographic template to a surgical drill guide by implementing computer transformation algorithms (1). A further form of differentiation of the computer guided systems can be the terms of their respective design for the drill guidance through the template. For instance, some systems use different drills with stops to achieve depth control, while others design surgical templates with sleeves of 
increasing diameter. In some systems the implants are inserted without using a guided device (99-102), free-hand, whereas other systems allow a guided implant placement as well (103-107). Some systems use different reference markers (e.g. gutta percha markers on the CBCT imaging) or do not use any references for performing the surgical procedures, while others use pre-installed reference points such as mini-implants $(107,108)$.

\section{I.5.1. Intraosseous temperature in guided osteotomy}

Misir et al. investigated the influence of surgical drill guides on the amount of heat generated at depths of 3.6, and $9 \mathrm{~mm}$ with and without the use of guides. The mean maximum temperatures were higher when a guide was used, and the highest temperature $\left(39.8{ }^{\circ} \mathrm{C}\right)$ was observed at a depth of $9 \mathrm{~mm}$. On the contrary, Bulloch and his colleagues (48) did not find a significant mean maximum temperature. Jeong et al.(44) did not find differences either in the temperature of the drill when they compared implant placement without raising a flap with the conventional method when a flap was raised. While intraosseous temperature changes during non-guided osteotomy have been investigated by numerous studies, there is a relative paucity of literature regarding such changes when guided osteotomy is performed. This is not surprising, as guided osteotomy has started to become widespread only recently. Still, the need for such studies does exist, and this was a major motivation for our investigations described in this thesis. 


\section{Aims and Hypotheses}

Based on the above, the work underlying the present thesis sought to find answers to the following questions:

1. How does the effect of the combination of low-speed drilling and cooled irrigation fluid influence intraosseous temperature elevation during guided and freehand implant surgery?

Our hypothesis was that with the combination of low-speed and cooled irrigation fluid we can control the temperature increment in such a way that with any of the drilling procedures it will be avoidable to do thermal damage to the bony structure.

2. How does drill wear and consequent intraosseous temperature elevation during freehand and guided bone drilling change, with special attention to the effect of metal-on metal contact during guided drilling? We hypothesized that the metal-onmetal contact would damage the surface of the drilling bits, and therefore it would be associated with significantly higher temperatures during the drilling procedures. 


\section{Investigation No. 1.}

\section{1. Purpose}

Our purpose was to investigate the combination of external irrigation at different temperatures and different drilling speeds and consequent intraosseous temperature elevation during freehand and guided bone drilling. Our study was designed to model temperature rise during implant site preparation.

\section{III.2. Materials and methods}

\section{III.2.1. Bone model}

Bovine ribs were used for the experiments because of their favourable anatomical and thermophysical characteristics. Davidson and James had already proved that bovine ribs are thermally isotropic and their conductivity is similar to the human mandible (109).

The densities of the cancellous and cortical bone of bovine ribs have been shown to be identical to human bone as it was concluded by computer tomography. According to this above mentioned study Yacker and Klein concluded that the cortical density of bovine ribs are to be around 1400 Hounsfield units (HU), whereas the cortical of the human mandible has a density value in the range between 1400 and $1600 \mathrm{HU}$ (32). The study conducted by Katranji and his colleagues (110) concluded that cortical bone thickness falls in a range of approximately 1.0-2.0 mm for edentulous and 1.6-2.0 for dentate bone. The specimens selected were in the above-mentioned range. Sener et al (84) proved in their study that the increase of intraosseous temperature elevation was greater in the cortical layer of the bone in comparison to the deeper parts of the drilled cavity. This finding has been confirmed by other studies as well $(69,111)$.

Bones were taken from the same animal, and the animals were not killed for the sake of the experiments. The specimens were all stored at a temperature of $-10^{\circ} \mathrm{C}$ in normal saline, when not used as it is suggested by Sedlin and Hirsch (112).

\section{III.2.2. Setup}

Drillings were performed for every step of the drilling sequence (diameters of 2.0, 2.5, 3.0, and $3.5 \mathrm{~mm}$ ) at a drilling speed of $800 \mathrm{rpm}$, comparing freehand versus guided surgery and the use of irrigation fluids at different temperatures $\left(20^{\circ} \mathrm{C}, 15^{\circ} \mathrm{C}\right.$, and $\left.10^{\circ} \mathrm{C}\right) .20$ drillings were performed in each of the 24 groups. 
For the groups where guided surgery was investigated and evaluated, a model surgical guide was designed. The guide had $2 \times 5$ guiding holes with metal sleeves (Fig. 1.) and 4 holes for the pins for the fixation of the guide. Entry points for the freehand groups were marked on the surface of the bone specimens with the help of the above-mentioned surgical guide (Fig. 1.).

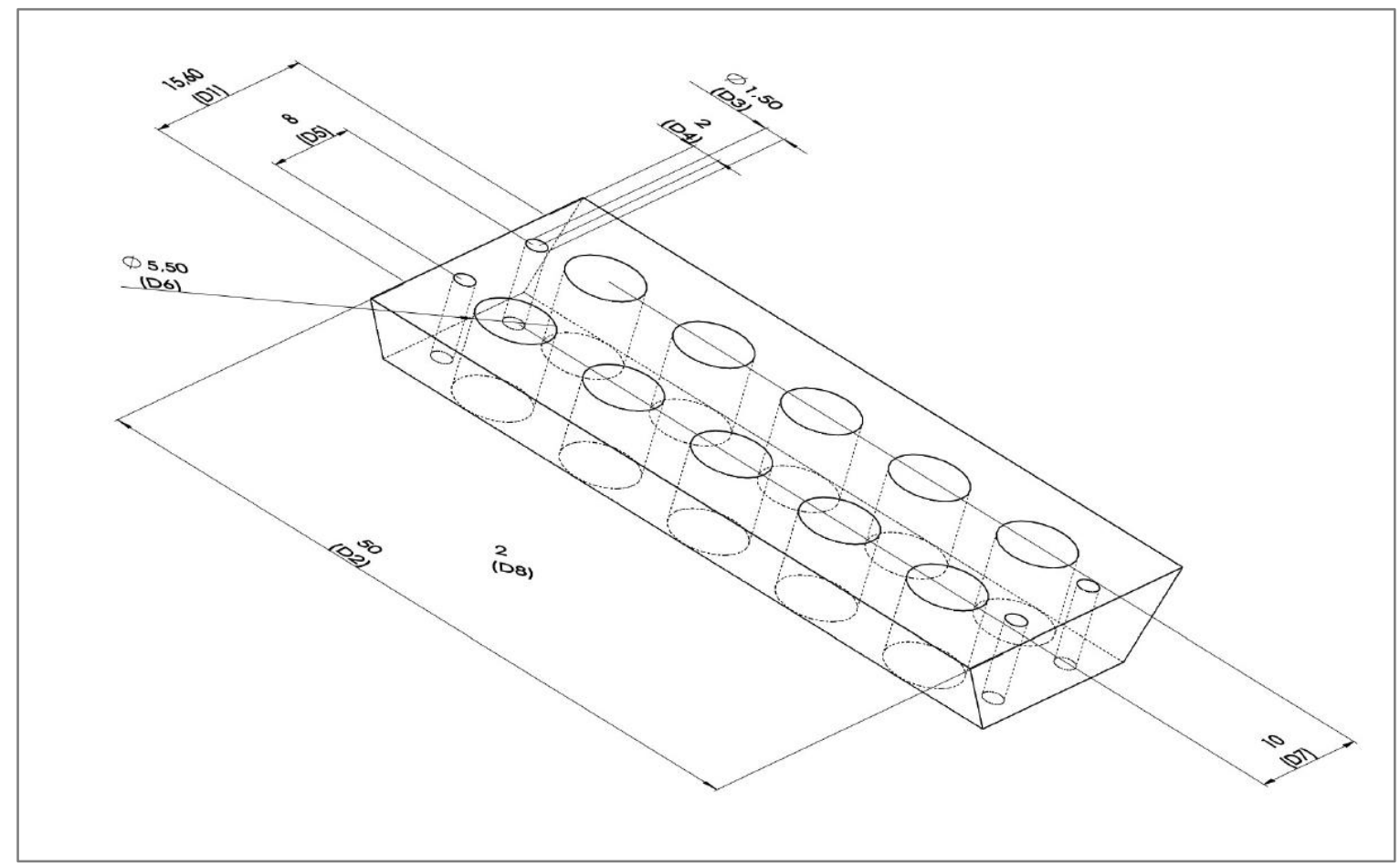

Figure 1. The surgical guide designed to fit the flat cortical rib bone specimens used in the study.

Studies suggest that the maximum temperature increment can be observed in the cortical layer of the bone $(69,84,111)$. Therefore, we performed temperature measurements in the cortical layer of the bone. K-type thermocouples were used for temperature measurements with a connected measurement device (HoldPeak 885A, HoldPeak; Zhuhai,Guangdong, China). The thermocouples were consistently placed into a cavity prepared with a $2.0-\mathrm{mm}$ diameter starting drill and a depth control of $1.8 \mathrm{~mm}$; therefore, we could ensure that the depth of the cavity never exceeded the cortical layer. The thermocouple was placed touching the lateral bony wall of the cavity being closer to the implant bed to be drilled, followed by tight filling with bone chips derived from rib specimens of the same animal and the hole was thoroughly sealed with plasticine to maintain adequate insulation (Fig. 2). 


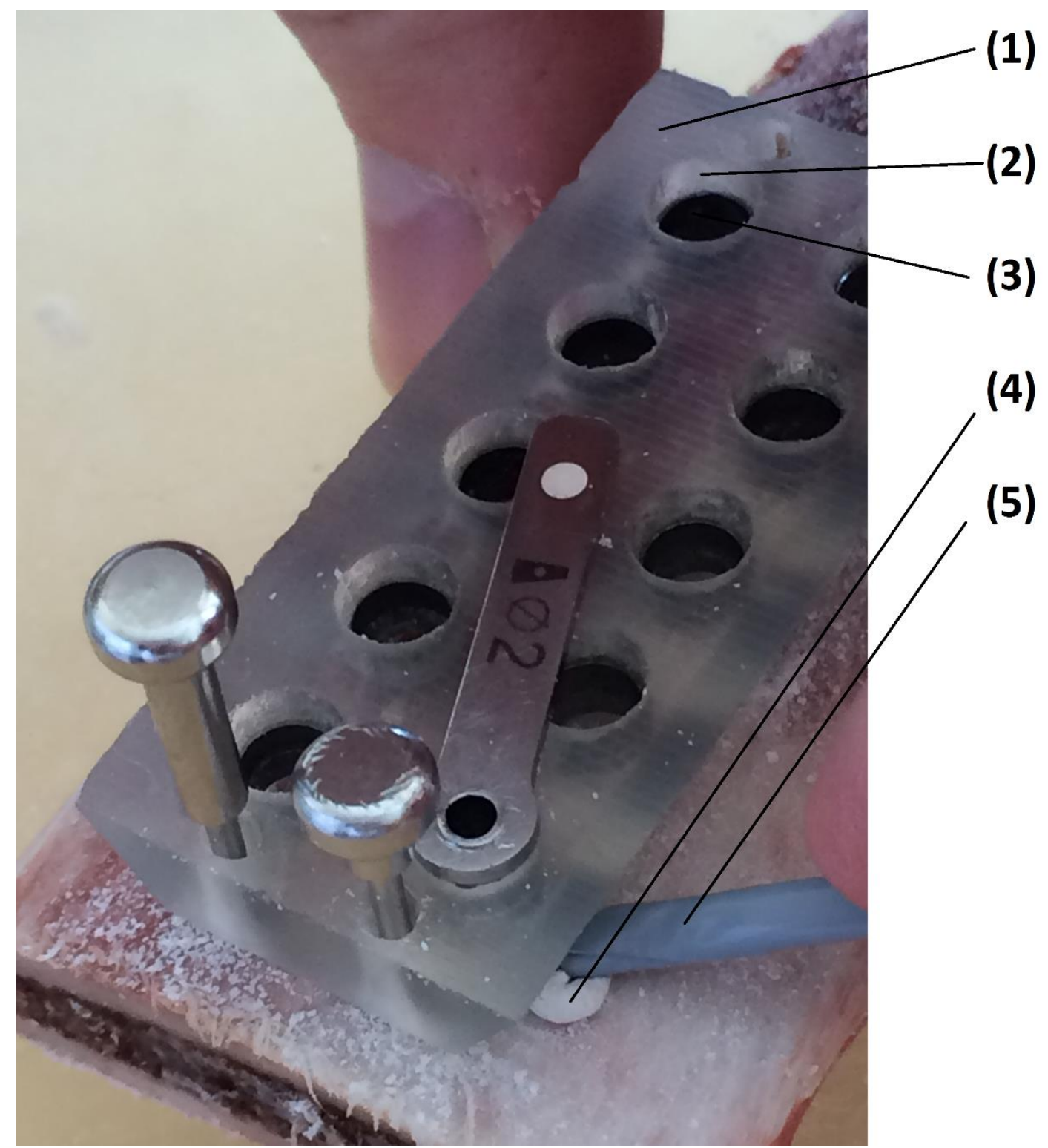

Figure 2. A close-up of the experimental setting. (1) Surgical guide, (2) guiding hole, (3) metal drill guide, (4) plasticine insulating the measurement bed, and (5) K-type thermocouple.

Measurement cavities were positioned directly underneath the metal sleeve of the surgical guide, being horizontally $1.75 \mathrm{~mm}$ from the $2.0 \mathrm{~mm}$ drilling canal, $1.50 \mathrm{~mm}$ from the 2.5 $\mathrm{mm}$ drilling canal, $1.25 \mathrm{~mm}$ from the $3.0-\mathrm{mm}$ drilling canal, and1.00mmfrom the $3.5 \mathrm{~mm}$ (final) drilling canal. To have comparable results, the measurement cavities were prepared in the same positions for the freehand groups. The precise position of the measurement cavities was determined by a 3D-printed guide, which could be anchored with pins in the same position as the model surgical guide (Fig. 3). 


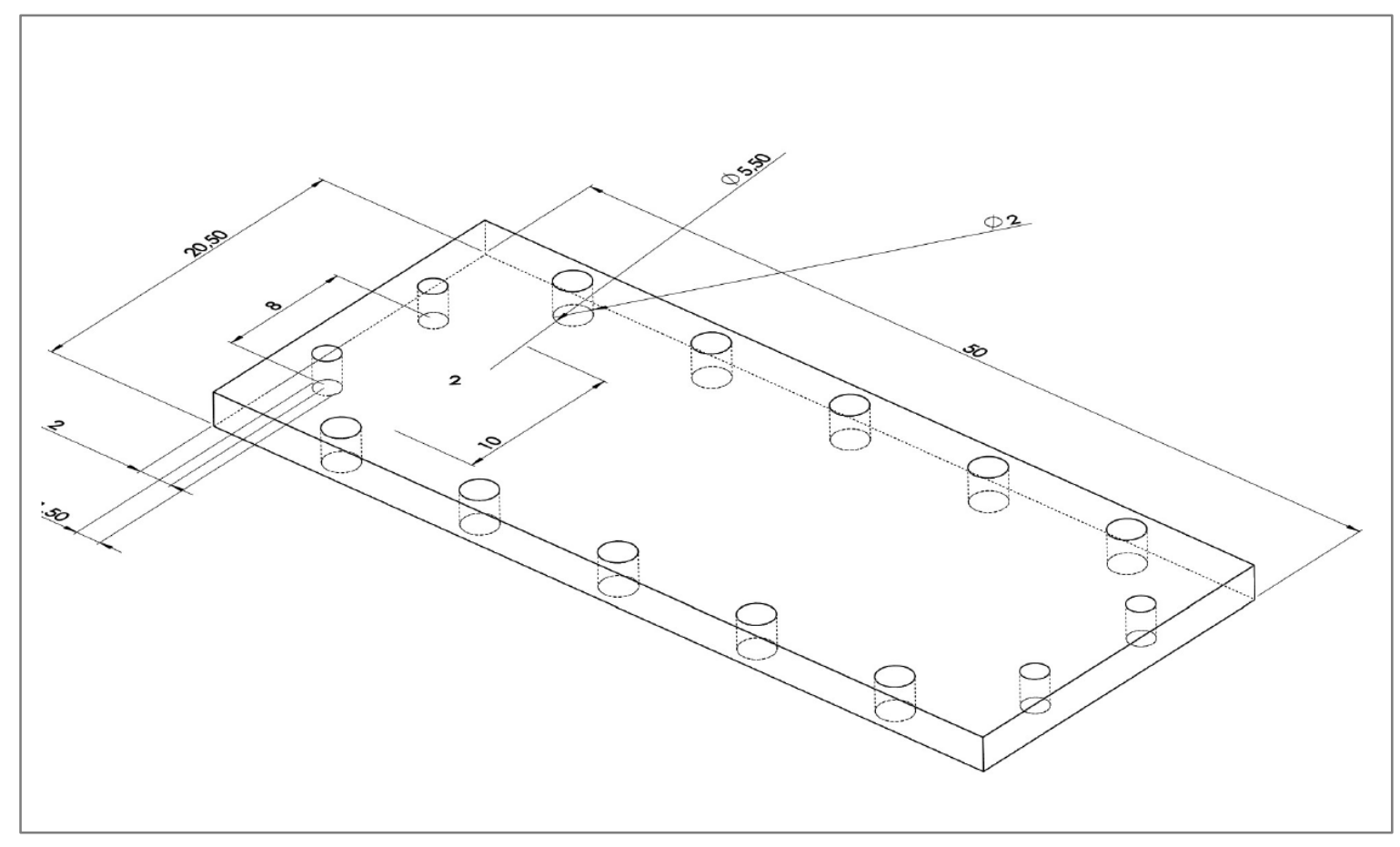

Figure 3. The surgical guide designed for the measurement bed preparation

A constant axial load of $2.0 \mathrm{~kg}$ was used, as it can be considered as a low hand pressure, and it is extensively used in the literature, as it can be seen in reviews concerning the topic as well $(14,16,26,82)$. A bench drill with adjustable drilling speed was used for the experiments (Bosch PBD 40; Bosch, Stuttgart, Germany).The specimens were heated up to a temperature of $37^{\circ} \mathrm{C}$. Drillings with temperature measurement were only executed if the baseline temperature of the bone was between $35^{\circ} \mathrm{C}$ to $37^{\circ} \mathrm{C}$.

Constantly controlled external irrigation was provided by a widely known, accepted and used surgical unit (W\&H Implantmed SI-923; W\&H, Bürmoos, Salzburg,Austria), and the standard cannula of the system was used $(\mathrm{W} \& \mathrm{H})$. The cannula was safely and preciesely attached to the drilling machine and it was directed toward the drill bit. Flow rate was 105 $\mathrm{mL} / \mathrm{min}$ as described by the manual of the system. The temperature of the irrigation fluid was either $20^{\circ} \mathrm{C} \pm 1^{\circ} \mathrm{C}$ or $15^{\circ} \mathrm{C} \pm 1^{\circ} \mathrm{C}$ or $10^{\circ} \mathrm{C} \pm 1^{\circ} \mathrm{C}$. The temperature of the irrigation fluid was always checked with an infrared thermometer before every measurement.

The full setup can be seen in Figure 4. All the drilling procedures were conducted in the same air-conditioned room, where the temperature was controlled within the range of $20^{\circ} \mathrm{C}$ $\pm 1^{\circ} \mathrm{C}$. 


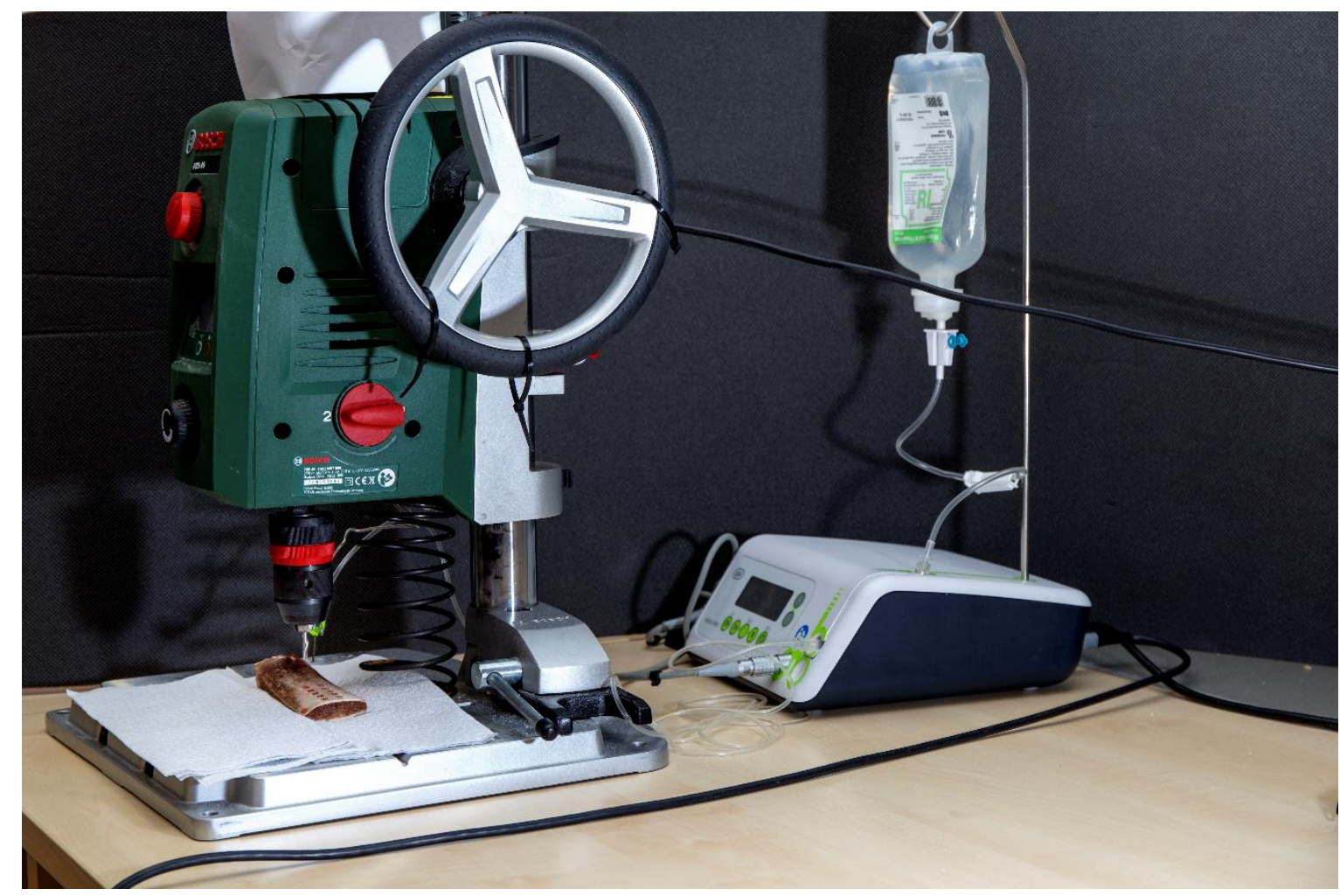

Figure 4. The experimental setting with the drill and the irrigation apparatus.

\section{III.2.3. Collection of data and statistical analysis}

Baseline and peak temperatures were collected to one decimal point in a spreadsheet file Microsoft Excel 2013 (v15.0) (Microsoft Corporation, Redmond, WA, USA). Temperature elevations were calculated as peak temperature minus baseline temperature to one decimal point using the spreadsheet. The values were statistically analysed using Statistica for Windows 10.0 (Statsoft, Tulsa, OK, USA). Normality of distributions was tested with the Shapiro-Wilk test. As for the hypothesis testing, one-way ANOVA with post-hoc Tukey HSD and Kruskal-Wallis ANOVA were used, as appropriate according to the normality of the distribution.

\section{III.3. Results}

Our results showing temperature rise due to drilling with a low drilling speed of $800 \mathrm{rpm}$, divided into groups by the drilling method (guided or freehand procedure) and the temperature of the irrigation fluid used for external cooling can be seen in Table 1. 
Table 1. Mean temperature rises and maximums of temperature rises for $800 \mathrm{rpm}$ drilling, groups of comparison divided by surgical method and temperature of the irrigation fluid

\begin{tabular}{|c|c|c|c|c|c|c|c|}
\hline $\begin{array}{l}\text { Grouping } \\
\text { number }\end{array}$ & $\begin{array}{c}\text { Diameter of the } \\
\text { drill }\end{array}$ & $\begin{array}{l}\text { Drilling speed } \\
\quad(\mathbf{r p m})\end{array}$ & $\begin{array}{l}\text { Guided/ } \\
\text { freehand }\end{array}$ & $\begin{array}{l}\text { Temperature } \\
\text { of irrigation } \\
\text { fluid }\left({ }^{\circ} \mathrm{C}\right)\end{array}$ & $\begin{array}{l}\text { Mean }(\mathrm{SD}) \\
\text { temperature } \\
\text { rise }\left({ }^{\circ} \mathrm{C}\right)\end{array}$ & $\begin{array}{l}\text { Maximum } \\
\text { temperature } \\
\text { rise }\left({ }^{\circ} \mathrm{C}\right)\end{array}$ & $\begin{array}{c}\text { Same diameter groups with } \\
\text { statistically significant difference } \\
\text { (grouping number, } * \mathbf{p}<\mathbf{0 . 0 5}, * * \text { - } \\
\mathbf{p}<\mathbf{0 . 0 1}, * * *-\mathbf{p}<\mathbf{0 . 0 0 1 )}\end{array}$ \\
\hline 1 & 2.0 & 800 & freehand & 10 & $-1.05(0.87)$ & 0.00 & $2 *, 3^{* * *}, 5^{* *}, 6^{* * *}$ \\
\hline 2 & 2.0 & 800 & freehand & 15 & $0.52(0.60)$ & 1.60 & $2 *$ \\
\hline 3 & 2.0 & 800 & freehand & 20 & $1.39(0.55)$ & 2.50 & $1 * * *, 4 * * *$ \\
\hline 4 & 2.0 & 800 & guided & 10 & $-0.07(0.48)$ & 1.10 & $3 * * *, 6 * * *$ \\
\hline 5 & 2.0 & 800 & guided & 15 & $0.66(0.90)$ & 2.60 & $1 * *$ \\
\hline 6 & 2.0 & 800 & guided & 20 & $1.40(0.46)$ & 2.00 & $1 * * *, 4 * * *$ \\
\hline 7 & 2.5 & 800 & freehand & 10 & $-0.23(0.39)$ & 0.50 & $8 * *, 9 * * *, 11^{* * *}, 12^{* * *}$ \\
\hline 8 & 2.5 & 800 & freehand & 15 & $1.08(0.59)$ & 2.50 & $7 * *, 10 *$ \\
\hline 9 & 2.5 & 800 & freehand & 20 & $1.65(0.50)$ & 2.70 & $7 * * *, 10 * * *$ \\
\hline 10 & 2.5 & 800 & guided & 10 & $-0.05(0.56)$ & 1.10 & $8^{*}, 9^{* * *}, 11^{*}, 12^{* *}$ \\
\hline 11 & 2.5 & 800 & guided & 15 & $1.27(0.96)$ & 3.40 & $7 * * *, 10 *$ \\
\hline 12 & 2.5 & 800 & guided & 20 & $1.35(0.51)$ & 2.20 & $7 * * *, 10^{* *}$ \\
\hline 13 & 3.0 & 800 & freehand & 10 & $0.28(0.41)$ & 1.20 & $14^{*}, 15^{* *}, 17^{* *}, 18^{* *}$ \\
\hline 14 & 3.0 & 800 & freehand & 15 & $1.62(0.66)$ & 3.10 & $13^{*}, 16^{*}$ \\
\hline 15 & 3.0 & 800 & freehand & 20 & $1.84(0.62)$ & 3.00 & $13^{* *}, 16^{* *}$ \\
\hline 16 & 3.0 & 800 & guided & 10 & $0.29(0.68)$ & 1.30 & $14^{*}, 15^{* *}, 17^{* *}, 18^{* *}$ \\
\hline 17 & 3.0 & 800 & guided & 15 & $1.98(1.46)$ & 4.60 & $13^{* *}, 16^{* *}$ \\
\hline 18 & 3.0 & 800 & guided & 20 & $1.83(0.52)$ & 2.90 & $13^{* *}, 16^{* *}$ \\
\hline 19 & 3.5 & 800 & freehand & 10 & $0.57(0.67)$ & 2.10 & $20 *, 21 * * *, 23 * *, 24 * * *$ \\
\hline 20 & 3.5 & 800 & freehand & 15 & $1.88(0.84)$ & 3.90 & $19 *, 22 *$ \\
\hline 21 & 3.5 & 800 & freehand & 20 & $2.30(0.60)$ & 3.60 & $19 * * *, 22 * * *$ \\
\hline 22 & 3.5 & 800 & guided & 10 & $0.72(0.53)$ & 1.60 & $20 *, 21 * * *, 23 *, 24 * *$ \\
\hline 23 & 3.5 & 800 & guided & 15 & $2.04(1.18)$ & 5.50 & $19 * *, 22 *$ \\
\hline 24 & 3.5 & 800 & guided & 20 & $2.24(1.13)$ & 4.80 & $19 * * *, 22 * *$ \\
\hline
\end{tabular}


In some instances, the use of irrigation fluid cooled to $10^{\circ} \mathrm{C}$ combined with low-speed drilling $(800 \mathrm{rpm})$ resulted in negative temperature changes as compared to the baseline. This might be the result of the cooling effect of the irrigation fluid being more pronounced than the heat producing effect of the drilling. This phenomenon was more pronounced for smaller drill diameters $(2.0$ and $2.5 \mathrm{~mm})$. No mean temperature change exceeded $+1.0^{\circ} \mathrm{C}$ when using irrigation fluid cooled to $10^{\circ} \mathrm{C}$, regardless of the drill diameter or the drilling method (freehand or guided). Moreover, the highest measured temperature change was below $+2.0^{\circ} \mathrm{C}$, except for the $3.5 \mathrm{~mm}$ freehand scenario, where a maximum temperature rise of $2.10^{\circ} \mathrm{C}$ occurred. The temperature change was significantly lower using irrigation fluid cooled to $10^{\circ} \mathrm{C}$ compared with the result with the same diameter drilling with irrigation at room temperature, for every investigated drill diameter, regardless of the drilling method. The use of irrigation fluid cooled to $15^{\circ} \mathrm{C}$ combined with low-speed drilling of $800 \mathrm{rpm}$ showed no significant reduction of temperature change, compared with irrigation at room temperature, regardless of both drill diameter and drilling method. Result of groups with the same irrigation fluid temperature, drilling method and drill diameter, comparing drilling with $800 \mathrm{rpm}$ to our previous results of drilling with $1200 \mathrm{rpm}$ can be seen in Table 2 (next page).

The use of irrigation fluid cooled to $10^{\circ} \mathrm{C}$ resulted in the diminishing of statistically significant differences $(\mathrm{P}=1.000)$ between the 2 drilling speeds, whereas the use of irrigation fluid at a controlled room temperature of $20^{\circ} \mathrm{C}$ has shown significantly higher temperature changes $(\mathrm{P}<0.001)$. The only exception is $2.0-\mathrm{mm}$ freehand drilling using $10^{\circ} \mathrm{C}$ irrigation fluid, whereas the $800 \mathrm{rpm}$ group showed significantly lower temperature rise $(\mathrm{P}<0.05)$; however, the temperature rise measured with 1200rpm drilling in the same circumstances has shown a markedly low temperature change as well 
Table 2. Mean temperature rises compared between groups with the same drill diameter, surgical method, and temperature of irrigation fluid, comparing groups with the drilling

\begin{tabular}{|c|c|c|c|c|c|}
\hline \multirow[b]{2}{*}{$\begin{array}{c}\text { Drill } \\
\text { diameter }\end{array}$} & \multirow[b]{2}{*}{$\begin{array}{l}\text { Guided/ } \\
\text { freehand }\end{array}$} & \multirow[b]{2}{*}{$\begin{array}{c}\text { Temperature } \\
\text { of irrigation } \\
\text { fluid }\left({ }^{\circ} \mathrm{C}\right)\end{array}$} & \multicolumn{2}{|c|}{ Compared groups } & \multirow[b]{2}{*}{$\begin{array}{c}\text { Statistically significant difference } \\
(*-\mathbf{p}<0.05, * *-\mathbf{p}<0.01, * * * \\
\mathbf{p}<0.001)\end{array}$} \\
\hline & & & $\begin{array}{l}\text { Mean (SD) temperature } \\
\text { rise (800 rpm group) }\left({ }^{\circ} \mathrm{C}\right)\end{array}$ & $\begin{array}{c}\text { Mean (SD) temperature } \\
\text { rise (1200 rpm group) }\left({ }^{\circ} \mathrm{C}\right)\end{array}$ & \\
\hline 2.0 & freehand & 10 & $-1.05(0.87)$ & $0.11(0.61)$ & $*$ \\
\hline 2.0 & freehand & 15 & $0.52(0.60)$ & $-0.04(1.15)$ & none \\
\hline 2.0 & freehand & 20 & $1.39(0.55)$ & $0.66(0.52)$ & none \\
\hline 2.0 & guided & 10 & $-0.07(0.48)$ & $1.44(0.46)$ & none \\
\hline 2.0 & guided & 15 & $0.66(0.90)$ & $1.74(0.73)$ & none \\
\hline 2.0 & guided & 20 & $1.40(0.46)$ & $2.56(0.92)$ & $*$ \\
\hline 2.5 & freehand & 10 & $-0.23(0.39)$ & $0.15(0.49)$ & none \\
\hline 2.5 & freehand & 15 & $1.08(0.59)$ & $-0.02(0.80)$ & none \\
\hline 2.5 & freehand & 20 & $1.65(0.50)$ & $1.13(0.51)$ & none \\
\hline 2.5 & guided & 10 & $-0.05(0.56)$ & $1.85(0.71)$ & none \\
\hline 2.5 & guided & 15 & $1.27(0.96)$ & $2.84(1.19)$ & none \\
\hline 2.5 & guided & 20 & $1.35(0.51)$ & $3.45(1.49)$ & $* * *$ \\
\hline 3.0 & freehand & 10 & $0.28(0.41)$ & $0.71(0.96)$ & none \\
\hline 3.0 & freehand & 15 & $1.62(0.66)$ & $0.10(0.76)$ & none \\
\hline 3.0 & freehand & 20 & $1.84(0.62)$ & $1.75(0.65)$ & none \\
\hline 3.0 & guided & 10 & $0.29(0.68)$ & $2.48(0.91)$ & none \\
\hline 3.0 & guided & 15 & $1.98(1.46)$ & $3.11(1.14)$ & none \\
\hline 3.0 & guided & 20 & $1.83(0.52)$ & $4.35(1.36)$ & $* * *$ \\
\hline 3.5 & freehand & 10 & $0.57(0.67)$ & $1.48(0.74)$ & none \\
\hline 3.5 & freehand & 15 & $1.88(0.84)$ & $1.40(0.58)$ & none \\
\hline 3.5 & freehand & 20 & $2.30(0.60)$ & $1.89(0.70)$ & none \\
\hline 3.5 & guided & 10 & $0.72(0.53)$ & $2.75(0.82)$ & none \\
\hline 3.5 & guided & 15 & $2.04(1.18)$ & $3.30(1.52)$ & none \\
\hline 3.5 & guided & 20 & $2.24(1.13)$ & $4.86(1.67)$ & $* * *$ \\
\hline
\end{tabular}


Finally, Table 3 shows that $800 \mathrm{rpm}$ guided drilling using $20^{\circ} \mathrm{C}$ irrigation fluid yielded similar results to $1200 \mathrm{rpm}$ guided drilling using $10^{\circ} \mathrm{C}$ irrigation, with the exception of 3.0 $\mathrm{mm}$

Table 3. Mean temperature rises of guided surgery groups with the same drill diameter. $800 \mathrm{rpm} / 20^{\circ} \mathrm{C}$ irrigation vs. $1200 \mathrm{rpm} / 10^{\circ} \mathrm{C}$ irrigation.

\begin{tabular}{|c|c|c|c|}
\hline & & \multicolumn{2}{|c|}{ Compared groups } \\
\hline $\begin{array}{c}\text { Diameter of } \\
\text { the drill }\end{array}$ & $\begin{array}{c}\text { Mean (SD) } \\
\text { Guided/ } \\
\text { femperature rise } \\
\mathbf{( 8 0 0} \mathbf{~ r p m}, \mathbf{2 0}^{\circ} \mathbf{C} \\
\text { irrigation) }\left({ }^{\circ} \mathbf{C}\right) \\
(\mathbf{n = 2 0} \text { for each } \\
\text { group) }\end{array}$ & $\begin{array}{c}\text { Mean }(\mathbf{S D}) \\
\text { temperature rise } \\
\left(\mathbf{1 2 0 0} \mathbf{~ r p m}, \mathbf{1 0}^{\circ} \mathbf{C}\right. \\
\text { irrigation group) } \\
\left({ }^{\circ} \mathbf{C}\right)(\mathbf{n}=\mathbf{2 0} \text { for each } \\
\text { group) }\end{array}$ \\
\hline 2.0 & guided & $1.40(0.46)$ & $1.44(0.46)$ \\
\hline 2.5 & guided & $1.35(0.51)$ & $1.85(0.71)$ \\
\hline 3.0 & guided & $1.83(0.52)$ & $2.48(0.91)$ \\
\hline 3.5 & guided & $2.24(1.13)$ & $2.75(0.82)$ \\
\hline
\end{tabular}




\section{Investigation No. 2.}

\section{IV.1. Purpose}

The study was designed in such a manner that we could precisely observe the effect of sterilization and extensive drill use by measuring the temperature elevation caused by the drill bits and visible damage to the cutting edge on magnified images at predetermined points of time (defined by the number of sterilization cycles and osteotomies). Regarding the data retrieved from the literature every drill bit is used for a mean of 2.5 osteotomies (implant cavity preparations) in 1 session (34).

\section{IV.2. Materials and methods}

\section{IV.2.1. Bone model}

The bone model used was the same as described above in the first investigation as it can also be seen with a detailed description on Fig 5 and Fig 6 .

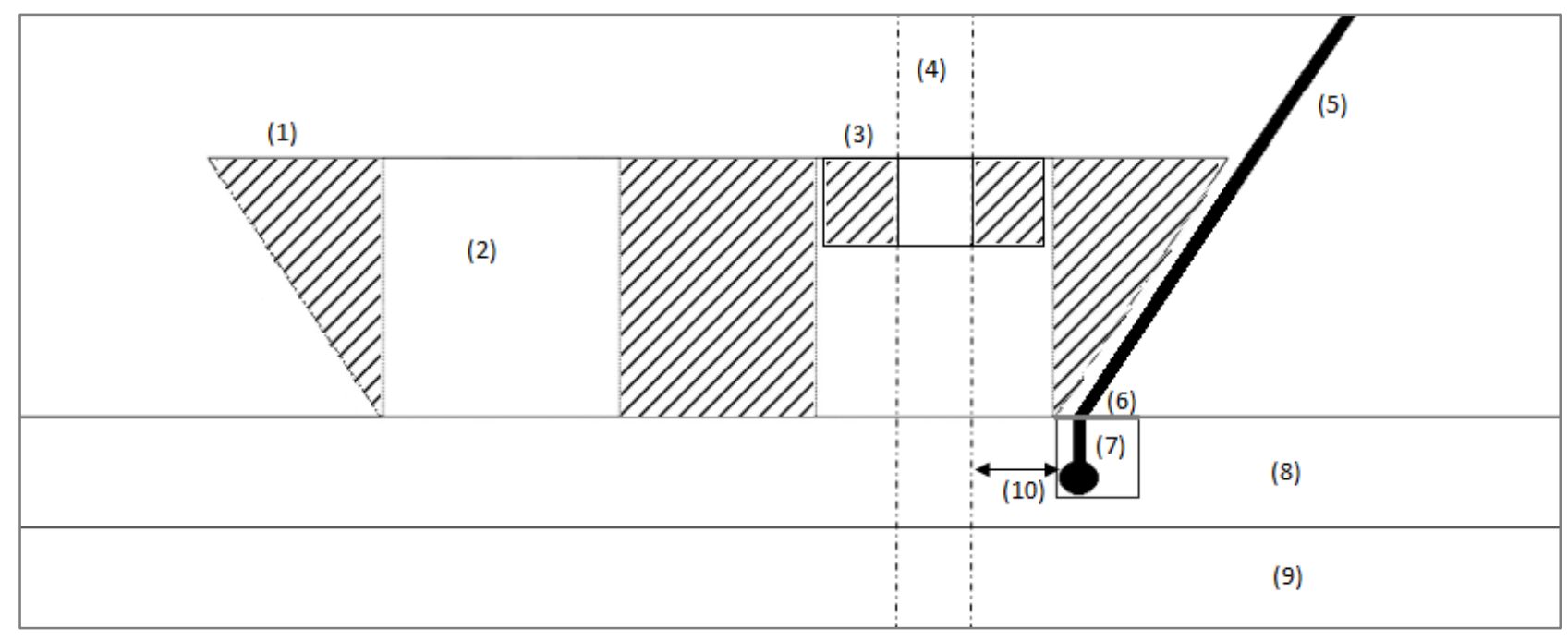

Figure 5. A schematic cross-section of the guided drilling setup. (1) surgical template, (2) guiding tunnel, (3) metal guiding sleeve, (4) drilling path, (5) the K-type thermocouple's wire, (6) plasticine insulation, (7) well for the K-type thermocouple (8), cortical bone, (9) cancellous bone, and (10) distance of the thermocouple from the drilling path. 


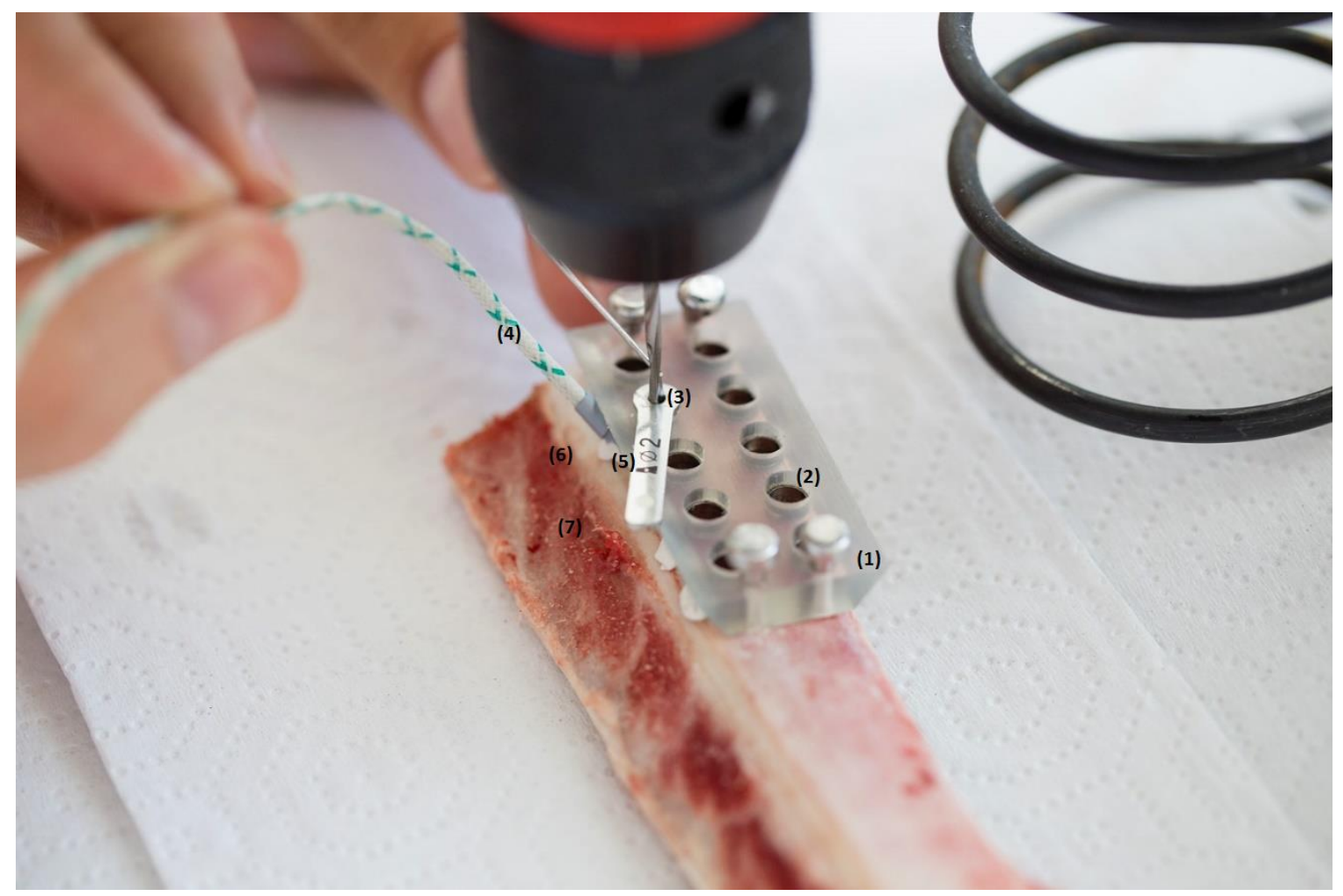

Figure 6. An actual in-experiment photograph of the setup. (1) surgical template, (2) guiding tunnel, (3) metal guiding sleeve, (4) the K-type thermocouple's wire, (5) plasticine insulation, (6) cortical bone, and (7) cancellous bone.

\section{IV.2.2. Setup}

Three different groups of sterilization were defined as follows: drill bits cleaned only by running water, no other chemical or physical contact (control protocol, $\mathrm{CP}$ ); drill bits cleaned with a soft brush using a standard disinfectant solution (Gigasept Instru AF, Schülke and Mayr, Germany), which was followed by 5 minutes of ultrasonic cleaning (Ultrasonic Cleaner JP-010, Digital Pro+, China), then a 20-minute-long sterilization program at $134^{\circ} \mathrm{C}$ (Quick Program S) in an autoclave (Vacuklav $24 \mathrm{~B}+$, MELAG,Germany)-soft protocol (SP); drill bits cleaned with a rough brush using the same disinfectant solution as in group SP, followed by a 50-minute-long sterilization program at $134^{\circ} \mathrm{C}$ (Universal Program) in the same autoclave as under SP (rough protocol, RP) Drill bits of $2.0 \mathrm{~mm}$ diameter were used from the tray of the SMART Guide System (Smart Dental Kft., Szeged, Hungary). The diameter was the beginning diameter of the full sequence $(2.5,3.0,3.5 \mathrm{~mm})$, which is used during every implant site preparation.

In each group, 3 drill bits were used. 
A maximum of 90 to 210 osteotomies were performed (in accordance to the speed of drilling, see Results). A single drilling lasted for a mean of 4 and 9 s, guided and freehand, respectively. Temperature measurements were performed after every 10th sterilization cycle (i.e., during every 30th drilling). The chisel edges and the cutting edges of the drill bits were also photographed at X30 magnification with the use of a toolmaker's microscope (TM-505; Kanagawa, Japan: Mitutoyo) before every temperature measurement cycle to observe and detect any visible physical damage. If not done freehand, every drilling was carried out through a 3D-printed surgical guide (DicomLab Kft., Szeged, as it can be seen on Fig. 1) especially designed for flat surfaces, meeting the requirements of clinical standards. The guides included a metal sleeve inserted in the guiding tunnel, which means that we were able to examine drill wear in a metal-on metal setup. Furthermore the bone segments were slowly warmed to a temperature of $36^{\circ} \mathrm{C}$ in sterile saline before temperature measurements. As the purpose of the experiments were to evaluate temperature elevations, a baseline temperature was also recorded. In all of the observed cases, this value was measured at the very first drilling of the given series, before any sterilization procedure. Osteotomies were conducted at room temperature, where the room temperature was controlled with an air-conditioning system at the level of $20^{\circ} \mathrm{C} \pm 1^{\circ} \mathrm{C}$.

Temperature measurement was performed with the same method and devices as described in the first investigation.

For the drilling the same device, controlled axial load of $2.0 \mathrm{~kg}$ and a constant external irrigation of $105 \mathrm{ml} / \mathrm{min}$ was used as describe in investigation number one. Osteotomies were performed at the speed levels of 800, 1200, 1500 and $2000 \mathrm{rpm}$.

Four main influential factors were considered: the absence or presence of the surgical guide ( 2 levels), the number of osteotomies performed ( 7 levels), the sterilization protocols (3 levels), and the drilling speed (4 levels). That meant, the data were recorded ina total of 168 conditions, and 9 measurements were taken in each condition. The resulting data set, defined by the described 4 main factors, contained 1134 temperature increment values (not 1512 as mathematically added, as the full sequence of 210 osteotomies and 70 sterilizations could only be carried out at $800 \mathrm{rpm}$, due to the consequent wear of the drill bits).

\section{IV.2.3. Collection of data and statistical analysis}

Temperature elevations were calculated by the subtraction of the baseline temperature from the peak temperature. 
The data were analysed in SPSS23.0 (Armonk, New York, United States: IBM). For the comprehensive analysis of the data, factorial ANOVA was used, with temperature increment as the dependent value, sterilization protocol, and drilling speed, and the total number of osteotomies performed as factors. For a more detailed analysis, the data were divided in 4 groups by the speed of drilling. Besides the descriptive statistics, groups defined by the sterilization protocol and the total number of osteotomies were compared with one-way ANOVA (with Tukey post hoc analysis).As multiple comparisons were performed, the level of significance was calculated individually for each and every analysis by the software. Wherever a specific difference is indicated not significant, it is indicated as such based on the output of the software described above.

\section{IV.4. Results}

\section{IV.4.1. Drill wear as a function of drilling speed}

At $800 \mathrm{rpm}$, it was possible to perform the maximum number of osteotomies $(210,70$ sterilization cycles). At $1200 \mathrm{rpm}$, only 120 osteotomies (40 sterilization cycles) were possible before the drills were worn beyond further use. At $1500 \mathrm{rpm}$, this dropped even further (90 osteotomies, 30 sterilization cycles), but this number did not change when the speed was increased to $2000 \mathrm{rpm}$. These findings were independent of whether the osteotomies were performed freehand or with a guiding template. Drill wear was readily observable at x30 magnification, especially at higher speeds. For an example, see Figure 7 


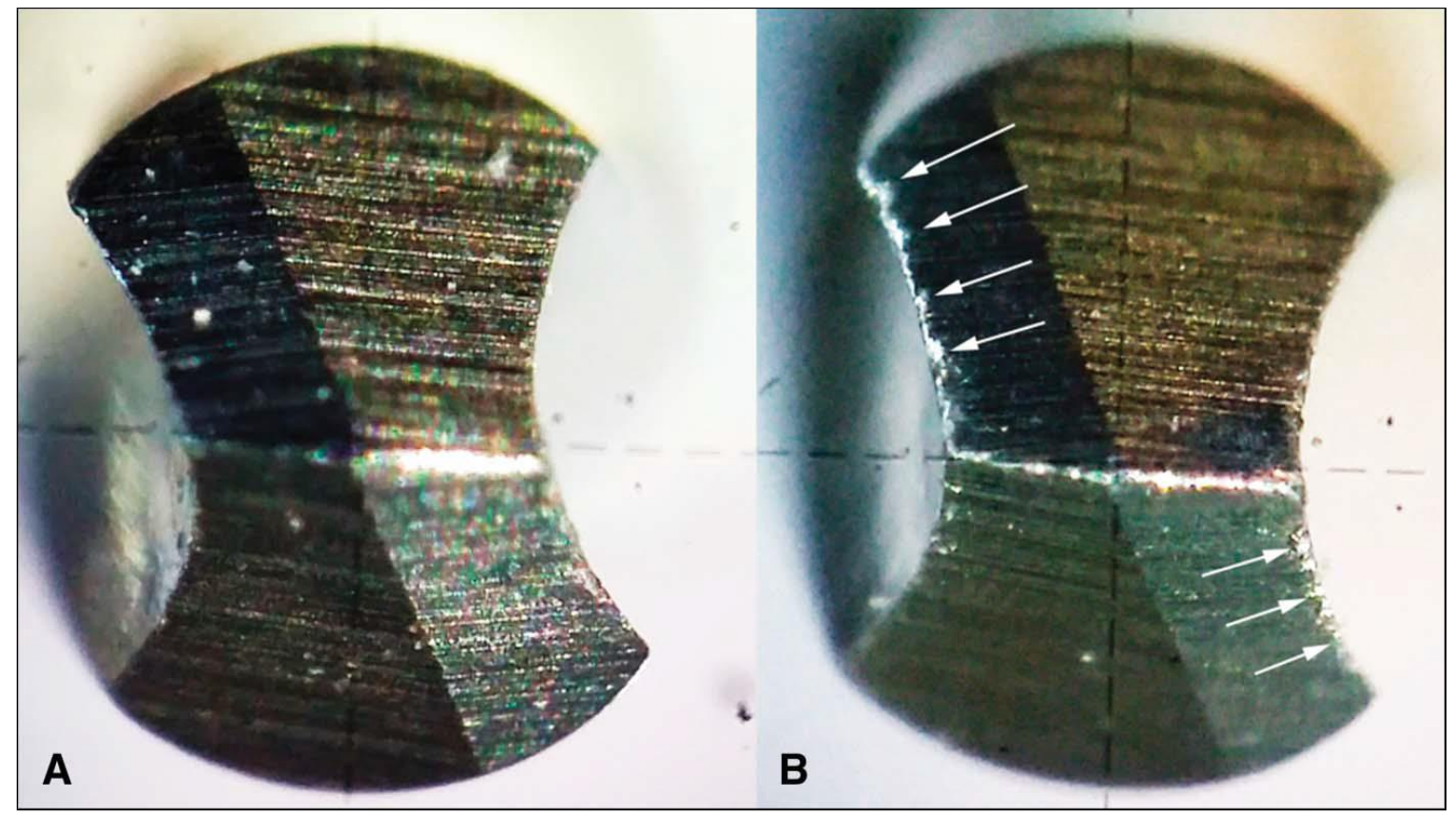

Figure 7. The edges of a drill bit before use (A) and after 30 osteotomies at $2000 \mathrm{rpm}$ (B). Notice that in (A) the edges area sharp, whereas in (B), sites of marked wear are detectable (as indicated by the white arrows); x30 magnification.

\section{IV.4.2. The effect of the individual factors on temperature elevation}

Factorial ANOVA was conducted to compare the main effects of drilling speed (DS, 4 levels), sterilization protocol (StP, 3 levels), the number of osteotomies (NO, 7 levels, expressed as the number of osteotomies at every 10th sterilization cycle up to 70), and surgical guide use (GU, 2 levels) on temperature elevation. All effects and interactions were statistically significant at $\mathrm{P}<0.000001$, except for the interactions $\mathrm{StP}^{*} \mathrm{GU} * \mathrm{NO}$ and Stp*GU*NO*DS, which were significant at $\mathrm{P}=0.002$ and $\mathrm{P}=0.009$, respectively. The main effect for DS yielded an F ratio of $\mathrm{F}(3.1008)=1588.18, \mathrm{P}<0.000001$, indicating a highly significant difference between mean temperature elevation values defined by the 4 possible speed settings. The main effect for StP yielded an F ratio of $\mathrm{F}(2,1008)=216.98$, $\mathrm{P}<0.000001$, indicating highly significant difference between mean temperature elevation values defined by the 3 sterilization protocols. The main effect for ND yielded an F ratio of $\mathrm{F}(6,1008)=538.09, \mathrm{P}<0.000001$, indicating highly significant difference between mean temperature elevation values defined by the number of osteotomies. The main effect for GU yielded an $\mathrm{F}$ ratio of $\mathrm{F}(3.1008)=1588.18, \mathrm{P}<0.000001$, indicating highly significant difference between mean temperature elevation values defined by the presence or lack of 
the surgical guide. As for the explanatory power of the model, $\mathrm{R}^{2}=0.896$ indicates that the chosen factors explain almost ninety percent of the variance in temperature elevation.

In the following detailed analysis, the most important findings are given by drilling speed. $\mathrm{P}$ values come from the Tukey post hoc test, unless otherwise stated.

\section{IV.4.3. Temperature increments at $800 \mathrm{rpm}$}

The descriptive statistics are shown in Table 1. The most important findings for guided osteotomies are as follows: at 800 revolutions per minute, the first significant temperature increment as compared to the baseline was detected after 90 osteotomies under the control sterilization protocol $(\mathrm{P}=0.00004)$ and the rough sterilization protocol $(\mathrm{P}=0.00007)$. Interestingly, significance was reached earlier under the soft sterilization protocol after only 60 osteotomies $(\mathrm{P}=0.04)$. Once statistical significance was reached, temperature continued to increase in significant steps $(\mathrm{P}<0.0001)$ under all protocols up to 210 osteotomies. The greatest mean increment at the 210th drilling was measured under the rough protocol $\left(10.06^{\circ} \mathrm{C} \pm 1.27^{\circ} \mathrm{C}\right)$. At 210 osteotomies, the difference was significant between $\mathrm{CP}$ and RP $(\mathrm{P}<0.0001)$ but not between CP and SP $(\mathrm{P}=0.11)$. SP and RP were significantly different $(\mathrm{P}<0.0001)$. The mean peak temperature was under the necrotic threshold for all protocols. As for freehand drilling, significance was reached in RP and SP after only 60 osteotomies ( $\mathrm{P}=0.00002$ and $\mathrm{P}=0.002$, respectively). $\mathrm{In} \mathrm{CP}$, significance was reached at 90 osteotomies $(\mathrm{P}=0.00001)$. Like the guided condition, once statistical significance was reached, temperature continued to increase in significant steps $(\mathrm{P}<0.0001)$ under all protocols up to 210 osteotomies. The greatest mean increment at the 210th drilling was measured in $\operatorname{RP}\left(7.24^{\circ} \mathrm{C} \pm 0.39^{\circ} \mathrm{C}\right)$, but the mean peak temperature remained under the necrotic threshold. At 210 osteotomies, the difference was significant between $\mathrm{CP}$ and both SP and RP $(P<0.0001)$. SP and RP were not significantly different $(\mathrm{P}=0.95)$. The mean peak temperature was under the necrotic threshold for all protocols (Table 4). A graphical summary of the findings is given in Figure 8. 
Table 4. Temperature increments at 800 RPM.

\begin{tabular}{|c|c|c|c|c|c|}
\hline Total number of drillings & Number of sterilizations & $\begin{array}{c}\text { Temperature } \\
\text { increment- guided } \\
\left({ }^{\circ} \mathrm{C}\right)\end{array}$ & SD & \begin{tabular}{|c|} 
Temperature \\
increment- \\
freehand $\left({ }^{\circ} \mathrm{C}\right)$
\end{tabular} & SD \\
\hline \multicolumn{6}{|c|}{ CONTROL } \\
\hline 0 & 0 & 2.38 & 0.77 & 1.68 & 0.58 \\
\hline 30 & 10 & 2.28 & 0.98 & 1.98 & 0.59 \\
\hline 60 & 20 & 3.16 & 0.84 & 2.27 & 0.42 \\
\hline 90 & 30 & 4.52 & 1.55 & 3.19 & 0.56 \\
\hline 120 & 40 & 4.30 & 1.40 & 3.56 & 0.39 \\
\hline 150 & 50 & 4.51 & 1.06 & 4.01 & 0.42 \\
\hline 180 & 60 & 4.89 & 1.07 & 4.41 & 0.65 \\
\hline 210 & 70 & 5.08 & 1.20 & 4.68 & 0.45 \\
\hline \multicolumn{6}{|c|}{ SOFT STERILIZATION } \\
\hline 0 & 0 & 1.81 & 0.59 & 1.79 & 0.31 \\
\hline 30 & 10 & 3.06 & 1.14 & 1.86 & 0.34 \\
\hline 60 & 20 & 3.73 & 1.12 & 2.68 & 0.28 \\
\hline 90 & 30 & 3.81 & 1.24 & 3.31 & 0.52 \\
\hline 120 & 40 & 5.36 & 0.83 & 4.28 & 0.32 \\
\hline 150 & 50 & 5.26 & 1.00 & 4.50 & 0.46 \\
\hline 180 & 60 & 5.57 & 0.94 & 5.14 & 0.49 \\
\hline 210 & 70 & 6.78 & 1.23 & 6.74 & 1.01 \\
\hline \multicolumn{6}{|c|}{ ROUGH STERILIZATION } \\
\hline 0 & 0 & 1.86 & 0.44 & 1.56 & 0.48 \\
\hline 30 & 10 & 2.49 & 0.26 & 2.02 & 0.38 \\
\hline 60 & 20 & 3.47 & 1.25 & 2.98 & 1.01 \\
\hline 90 & 30 & 4.47 & 0.98 & 3.60 & 0.47 \\
\hline 120 & 40 & 5.67 & 1.23 & 4.71 & 0.57 \\
\hline 150 & 50 & 6.82 & 1.35 & 5.20 & 0.45 \\
\hline 180 & 60 & 7.93 & 0.80 & 6.31 & 0.51 \\
\hline 210 & 70 & 10.06 & 1.27 & 7.24 & 0.39 \\
\hline
\end{tabular}




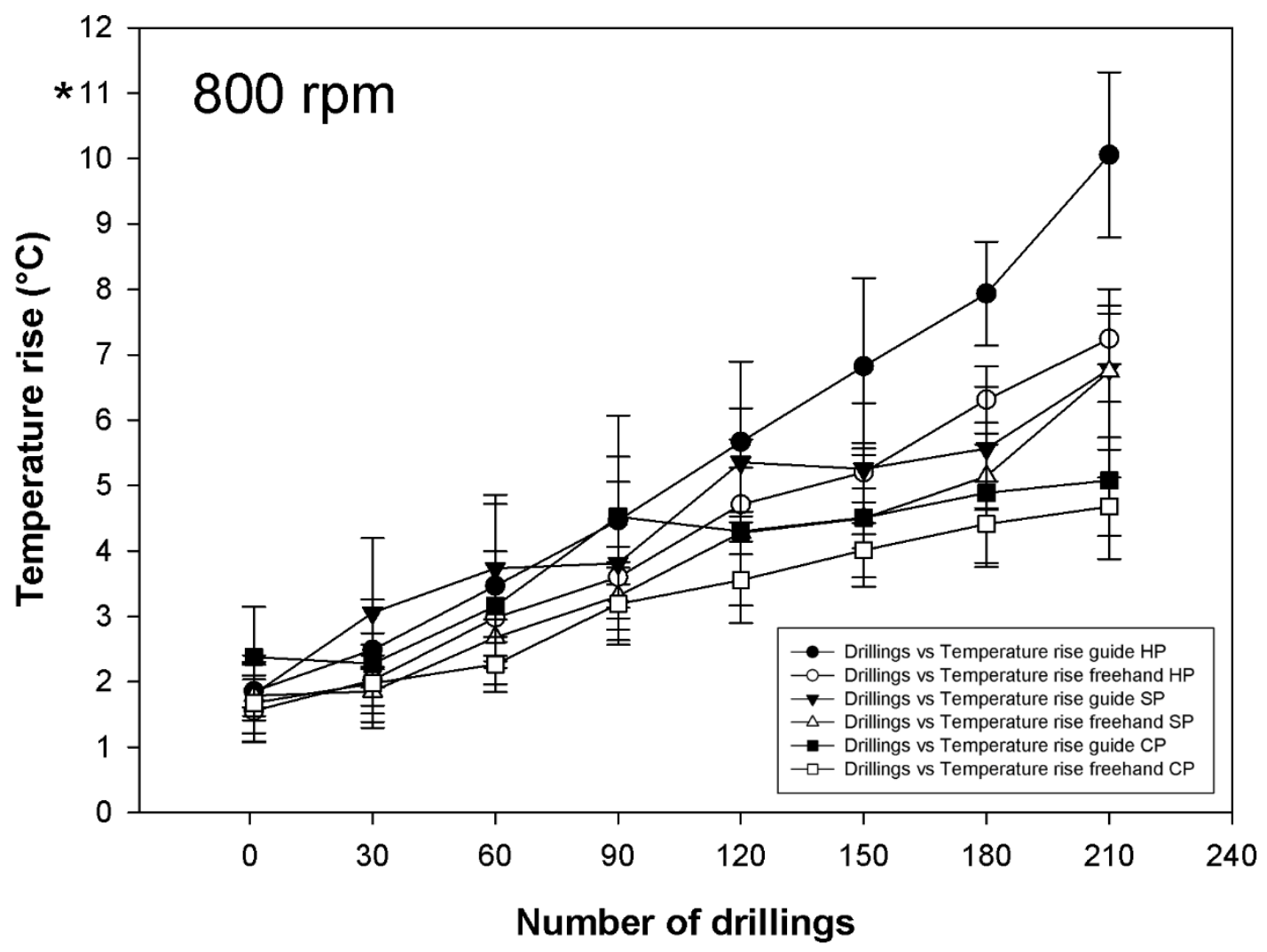

Figure 8. Temperature increments at $800 \mathrm{rpm}$. The baseline is $36^{\circ} \mathrm{C}$. The necrotic threshold $\left(^{*}\right)$ is at $11^{\circ} \mathrm{C}$ increment $\left(47^{\circ} \mathrm{C}\right)$. HP: hard/rough sterilization protocol; SP: soft sterilization protocol; CP: control sterilization protocol.

\section{IV.4.4. Temperature increments at 1200 rpm}

The descriptive statistics are shown in Table 2. As for guided osteotomies, the first significant temperature increment as compared to the baseline was detected after 30 osteotomies under $\mathrm{CP}(\mathrm{P}<0.01)$ and $\mathrm{SP}(\mathrm{P}<0.01)$. Unexpectedly, under $\mathrm{RP}$, it took longer, 60osteotomies, to reach statistical significance $(\mathrm{P}<0.001)$. Once statistical significance was reached, temperature continued to increase in significant steps $(\mathrm{P}<0.001)$ under all protocols up to 120 osteotomies. The greatest mean increment at the 120th drilling was measured under the rough protocol $\left(11.28^{\circ} \mathrm{C} \pm 1.12^{\circ} \mathrm{C}\right)$. At 120 osteotomies, the difference was significant between $\mathrm{CP}$ and both $\mathrm{SP}$ and $\mathrm{RP}(\mathrm{P}<0.001)$. SP and RP were not significantly different $(\mathrm{P}=1.00)$. The mean peak temperature reached or slightly exceeded the necrotic threshold under both SP and RP but not under CP. With freehand drilling, statistically significant temperature increment was reached after only 30 osteotomies, regardless of the sterilization protocol $(\mathrm{P}<0.001)$. From 30 osteotomies on, the temperature 
increased in significant steps. The greatest mean increment at the 120th drilling was measured under the rough protocol $\left(7.62^{\circ} \mathrm{C} \pm 0.30^{\circ} \mathrm{C}\right)$. At 120 osteotomies, the difference was significant between $\mathrm{CP}$ and RP $(\mathrm{P}<0.01)$. No significant difference was found between $\mathrm{CP}$ and $\mathrm{SP}(\mathrm{P}=0.11)$. SP and RP were not significantly different $(\mathrm{P}=0.99)$. The mean peak temperature remained under the necrotic threshold, regardless of the sterilization protocol (Table 5, Figure 9).

Table 5. Temperature increments at 1200 RPM.

\begin{tabular}{|c|c|c|c|c|c|}
\hline Total number of drillings & Number of sterilizations & $\begin{array}{c}\text { Temperature } \\
\text { increment- guided } \\
\left({ }^{\circ} \mathrm{C}\right)\end{array}$ & SD & $\begin{array}{l}\text { Temperature } \\
\text { increment- } \\
\text { freehand }\left({ }^{\circ} \mathbf{C}\right)\end{array}$ & SD \\
\hline \multicolumn{6}{|c|}{ CONTROL } \\
\hline 0 & 0 & 3.44 & 0.73 & 2.70 & 0.40 \\
\hline 30 & 10 & 5.58 & 0.90 & 4.37 & 0.48 \\
\hline 60 & 20 & 5.81 & 1.08 & 5.00 & 0.98 \\
\hline 90 & 30 & 7.73 & 1.28 & 5.78 & 0.92 \\
\hline 120 & 40 & 8.27 & 0.80 & 6.44 & 0.52 \\
\hline \multicolumn{6}{|c|}{ SOFT STERILIZATION } \\
\hline 0 & 0 & 3.56 & 1.58 & 2.57 & 0.31 \\
\hline 30 & 10 & 5.50 & 1.10 & 4.30 & 0.46 \\
\hline 60 & 20 & 7.37 & 1.20 & 5.47 & 0.53 \\
\hline 90 & 30 & 10.10 & 1.67 & 6.23 & 0.64 \\
\hline 120 & 40 & 11.02 & 1.12 & 7.29 & 0.37 \\
\hline \multicolumn{6}{|c|}{ ROUGH STERILIZATION } \\
\hline 0 & 0 & 3.26 & 0.94 & 2.51 & 0.39 \\
\hline 30 & 10 & 4.31 & 0.81 & 4.64 & 0.70 \\
\hline 60 & 20 & 7.49 & 1.14 & 6.00 & 0.44 \\
\hline 90 & 30 & 9.56 & 1.46 & 6.47 & 0.52 \\
\hline 120 & 40 & 11.28 & 1.12 & 7.62 & 0.30 \\
\hline
\end{tabular}




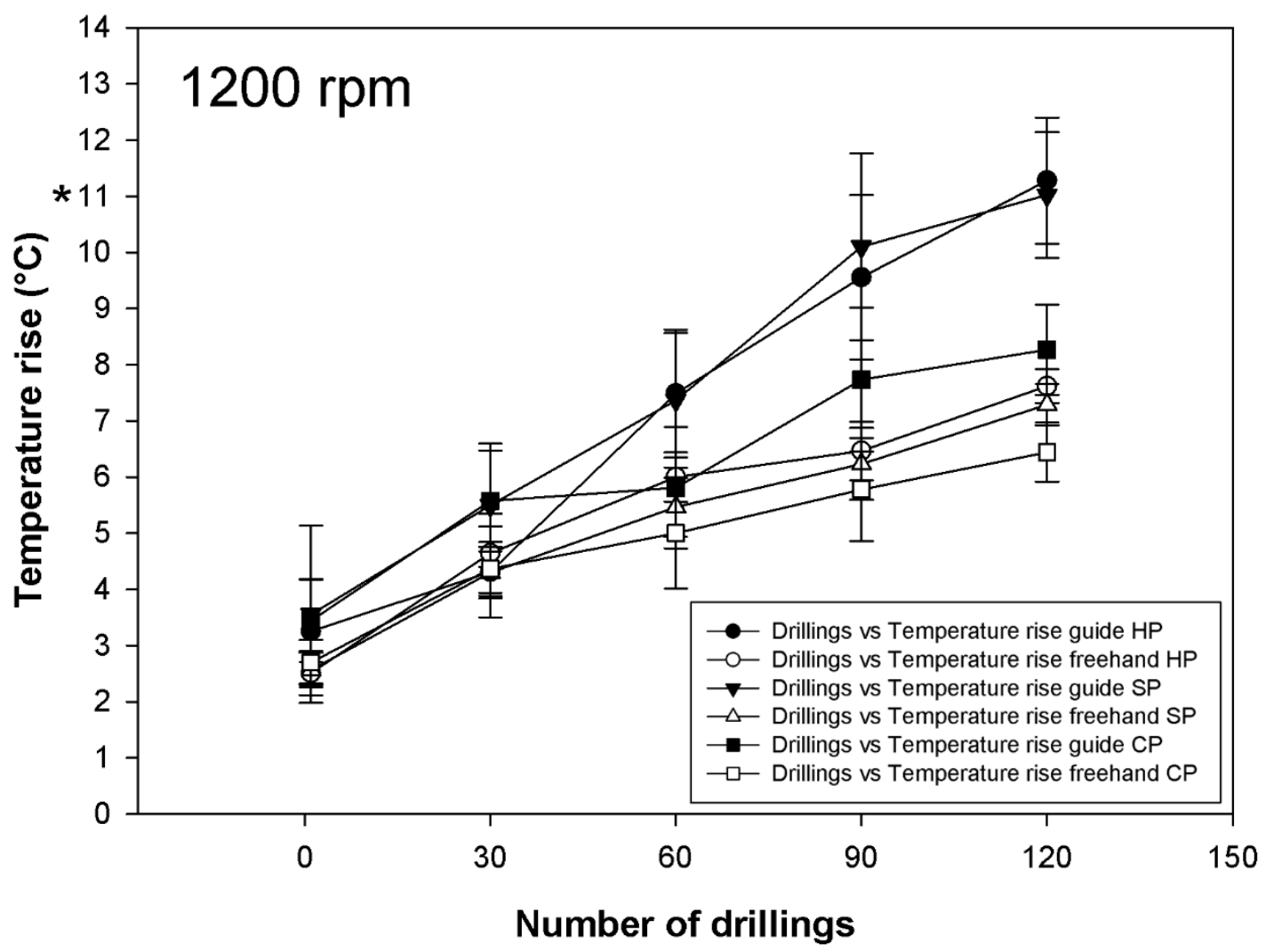

Figure 9. Temperature increments at $1200 \mathrm{rpm}$. The baseline is $36{ }^{\circ} \mathrm{C}$. The necrotic threshold is at $11^{\circ} \mathrm{C}$ increment $\left(47^{\circ} \mathrm{C}\right)$. HP: hard/rough sterilization protocol; SP: soft sterilization protocol; CP: control sterilization protocol.

\section{IV.4.5. Temperature Increments at 1500 rpm}

The descriptive statistics are shown in Table 6. As for the guided osteotomies, the first significant temperature increment as compared to the baseline was detected after 30 osteotomies under RP (P < 0.001). Under SP, it took 60 osteotomies to reach significance ( $\mathrm{P}<0.001)$. Regarding osteotomies with drills treated according to $\mathrm{CP}$, significance was reached only at 90 osteotomies, which was the maximum at this speed $(\mathrm{P}<0.01)$. Once statistical significance was reached, temperature continued to increase in significant steps ( $\mathrm{P}<0.001)$ up to 90 osteotomies. The greatest mean increment at the 90th drilling was measured under the rough protocol $\left(9.94^{\circ} \mathrm{C} \pm 0.58^{\circ} \mathrm{C}\right)$. At 90 osteotomies, the difference was significant between $\mathrm{CP}$ and both $\mathrm{SP}$ and RP $(\mathrm{P}<0.001)$. SP and RP were not significantly different $(\mathrm{P}=1.00)$. The mean peak temperature remained under the necrotic threshold, regardless of the sterilization protocol. With freehand drilling, statistically 
significant temperature increment was reached at 30 osteotomies under both RP and SP $(\mathrm{P}<$ 0.001 and $\mathrm{P}<0.01$, respectively) and at 60 osteotomies under $\mathrm{CP}(\mathrm{P}<0.01)$. Once statistical significance was reached, temperature continued to increase in significant steps $(\mathrm{P}<0.001)$ up to 90 osteotomies. The greatest mean increment at the 90th drilling was measured under the rough protocol $\left(8.04^{\circ} \mathrm{C} \pm 0.72^{\circ} \mathrm{C}\right)$. At 90 osteotomies, the difference was significant between $\mathrm{CP}$ and RP $(\mathrm{P}<0.01)$, but no significant difference was found between $\mathrm{CP}$ and SP $(\mathrm{P}=0.85)$. SP and RP were not significantly different $(\mathrm{P}=0.32)$. The mean peak temperature remained under the necrotic threshold, regardless of the sterilization protocol (Table 6, Figure 10).

Table 6. Temperature increments at $1500 \mathrm{rpm}$.

\begin{tabular}{|c|c|c|c|c|c|}
\hline Total number of drillings & Number of sterilizations & $\begin{array}{c}\text { Temperature } \\
\text { increment- guided } \\
\left({ }^{\circ} \mathbf{C}\right)\end{array}$ & SD & $\begin{array}{c}\text { Temperature } \\
\text { increment- } \\
\text { freehand }\left({ }^{\circ} \mathbf{C}\right)\end{array}$ & SD \\
\hline \multicolumn{6}{|c|}{ CONTROL } \\
\hline 0 & 0 & 5.68 & 0.75 & 4.34 & 0.59 \\
\hline 30 & 10 & 5.46 & 0.98 & 5.26 & 0.56 \\
\hline 60 & 20 & 5.89 & 1.16 & 5.83 & 0.56 \\
\hline 90 & 30 & 6.88 & 1.07 & 6.89 & 0.66 \\
\hline \multicolumn{7}{|c|}{ SOFT STERILIZATION } \\
\hline 0 & 0 & 5.84 & 1.13 & 4.24 & 0.49 \\
\hline 30 & 10 & 5.82 & 0.75 & 5.44 & 0.34 \\
\hline 60 & 20 & 7.28 & 0.71 & 6.17 & 0.49 \\
\hline 90 & 30 & 9.83 & 0.75 & 7.36 & 0.55 \\
\hline \multicolumn{7}{|c|}{ ROUGH STERILIZATION } & & \\
\hline 0 & 0 & 5.31 & 0.58 & 4.40 & 0.55 \\
\hline 30 & 10 & 7.48 & 0.60 & 6.33 & 0.56 \\
\hline 60 & 20 & 8.03 & 0.82 & 6.69 & 0.68 \\
\hline 90 & 30 & 0.58 & 8.04 & 0.72 \\
\hline
\end{tabular}




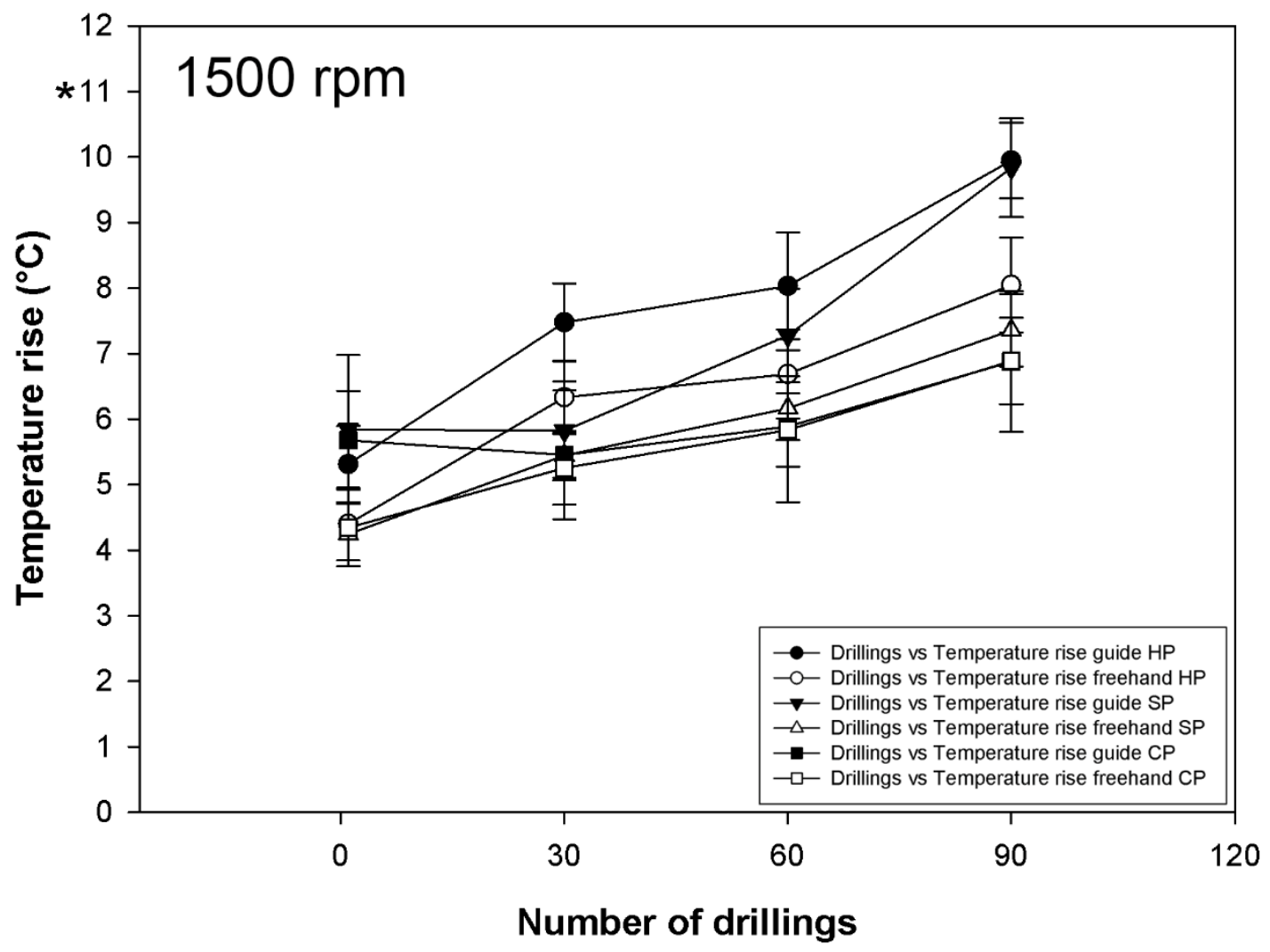

Figure 10. Temperature increments at $1500 \mathrm{rpm}$. The baseline is $36^{\circ} \mathrm{C}$. The necrotic threshold is at $11^{\circ} \mathrm{C}$ increment $\left(47^{\circ} \mathrm{C}\right)$. HP: hard/rough sterilization protocol; SP: soft sterilization protocol; CP: control sterilization protocol.

\section{IV.4.6. Temperature Increments at 2000 rpm}

The descriptive statistics are shown in Table 4. As for guided osteotomies, the first significant temperature increment, as compared to the baseline was detected at 60 osteotomies under RP and SP $(\mathrm{P}<0.001)$. Under $\mathrm{CP}$, significance was reached at the maximum 90 osteotomies $(\mathrm{P}<0.001)$. Under SP, it took 60 osteotomies to reach significance $(\mathrm{P}<0.001)$. Once statistical significance had been reached, temperature continued to increase in significant steps $(\mathrm{P}<0.001)$ up to 90 osteotomies. The greatest mean increment at the 90th drilling was measured under the rough protocol $\left(12.48^{\circ} \mathrm{C} \pm\right.$ $\left.1.39^{\circ} \mathrm{C}\right)$. At 90 osteotomies, the difference was significant between $\mathrm{CP}$ and $\mathrm{RP}(\mathrm{P}<0.05)$ but not between $\mathrm{CP}$ and $\mathrm{SP}(\mathrm{P}=1.00)$. SP and $\mathrm{RP}$ were significantly different $(\mathrm{P}<0.001)$. The mean peak temperature exceeded the necrotic threshold under RP. With freehand drilling, statistically significant temperature increment was reached at 30 osteotomies under RP $(\mathrm{P}<0.05), 60$ osteotomies under SP $(\mathrm{P}<0.001)$, and 90 osteotomies under $\mathrm{CP}(\mathrm{P}<$ 0.001). Once statistical significance was reached, temperature continued to increase in 
significant steps $(\mathrm{P}<0.001)$ up to 90 osteotomies. The greatest mean increment at the 90th drilling was measured under the rough protocol $\left(9.54^{\circ} \mathrm{C} 60.73^{\circ} \mathrm{C}\right)$. At 90 osteotomies, the difference was significant between $\mathrm{CP}$ and $\mathrm{RP}(\mathrm{P}<0.05)$, but no significant difference was found between $\mathrm{CP}$ and $\mathrm{SP}(\mathrm{P}=0.99)$. SP and $\mathrm{RP}$ were not significantly different $(\mathrm{P}=0.45)$. The mean peak temperature remained under the necrotic threshold, regardless of the sterilization protocol (Table 7, Figure 11).

Table 7. Temperature increments at $2000 \mathrm{rpm}$.

\begin{tabular}{|c|c|c|c|c|c|}
\hline Total number of drillings & Number of sterilizations & $\begin{array}{c}\text { Temperature } \\
\text { increment- guided } \\
\left({ }^{\circ} \mathrm{C}\right)\end{array}$ & SD & $\begin{array}{l}\text { Temperature } \\
\text { increment- } \\
\text { freehand }\left({ }^{\circ} \mathbf{C}\right)\end{array}$ & SD \\
\hline \multicolumn{6}{|c|}{ CONTROL } \\
\hline 0 & 0 & 6.88 & 1.21 & 5.47 & 0.86 \\
\hline 30 & 10 & 6.92 & 1.28 & 6.37 & 0.78 \\
\hline 60 & 20 & 7.81 & 0.97 & 6.84 & 0.82 \\
\hline 90 & 30 & 10.77 & 1.55 & 8.33 & 0.80 \\
\hline \multicolumn{6}{|c|}{ SOFT STERILIZATION } \\
\hline 0 & 0 & 7.54 & 0.71 & 5.58 & 0.79 \\
\hline 30 & 10 & 7.43 & 0.70 & 6.77 & 0.69 \\
\hline 60 & 20 & 8.81 & 0.58 & 7.46 & 0.55 \\
\hline 90 & 30 & 10.58 & 0.96 & 8.71 & 0.93 \\
\hline \multicolumn{6}{|c|}{ ROUGH STERILIZATION } \\
\hline 0 & 0 & 6.97 & 0.97 & 5.82 & 0.91 \\
\hline 30 & 10 & 8.39 & 0.79 & 7.14 & 0.52 \\
\hline 60 & 20 & 9.21 & 0.83 & 7.72 & 0.48 \\
\hline 90 & 30 & 12.48 & 1.39 & 9.54 & 0.73 \\
\hline
\end{tabular}




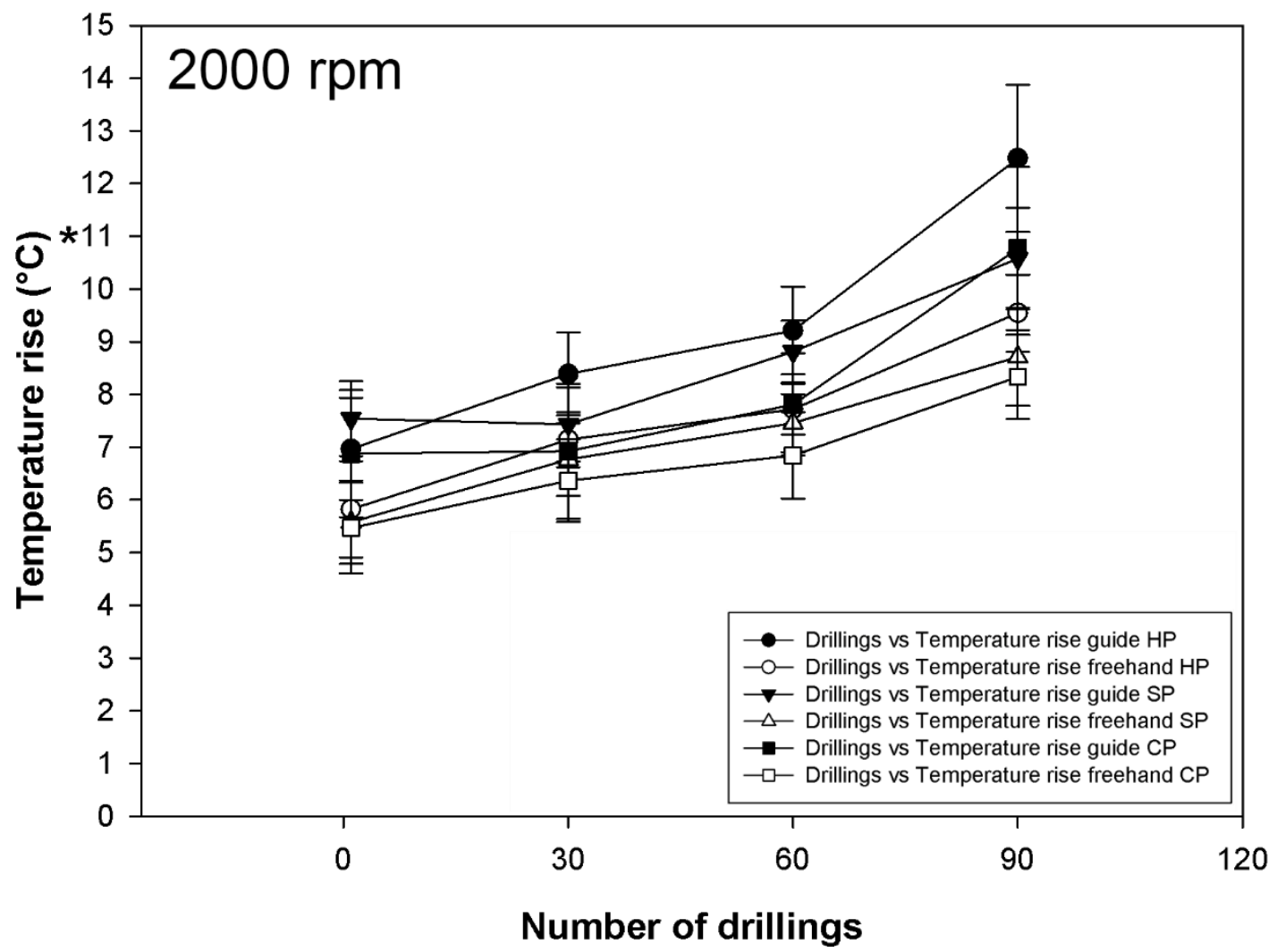

Figure 11. Temperature increments at $2000 \mathrm{rpm}$. The baseline is $36^{\circ} \mathrm{C}$. The necrotic threshold is at $11^{\circ} \mathrm{C}$ increment $\left(47^{\circ} \mathrm{C}\right)$. HP: hard/rough sterilization protocol; SP: soft sterilization protocol; $\mathrm{CP}$ : control sterilization protocol. 


\section{Discussion}

Heat elevation during implant site preparation by osteotomy is a problem that has been discussed in the literature since the 1970s (61), as by that time it had long been established that temperatures comparable with those observed during dental osteotomy can cause permanent tissue damage (113). Naturally, the most important goal was to establish a safety threshold. It was Eriksson and colleagues who studied this question in detail. In their vital microscopic rabbit study, they demonstrated changes in the blood flow, resorption of fat cells, and irreversible bone damage after a 1-minute exposure to $53^{\circ} \mathrm{C}(25)$. Later, they refined that value to between $47^{\circ} \mathrm{C}$ and $50^{\circ} \mathrm{C}$ (1-minute exposure) (24), and it is after their work that we consider $47^{\circ} \mathrm{C}$ to be the safety threshold (or necrotic threshold) today. How much does intraosseous temperature elevate during osteotomy? Most of the studies were done in vitro to find out about this, and values from $40^{\circ} \mathrm{C}(61)$ to the extreme $130^{\circ} \mathrm{C}(85)$ were reported. The reason for this huge dispersion is most probably that, frictional heat generation is influenced by several factors from the application of cooling through the width of the drill bit. There is a consensus, though, that cooling is a sine qua non of safe implant site preparation. In their thorough in vivo study in sheep, Trisi and colleagues demonstrated that there is a relationship between the quality and quantity of cooling (irrigation) and periimplant bone resorption (114), which can reach levels that risk implant success. It was also Trisi and colleagues who studied osseointegration in vivo in a way that the designated implant sites were divided into 2 groups and preheated to $50^{\circ} \mathrm{Cand} 60^{\circ} \mathrm{C}$, respectively. The authors expressed the success of 2-month osseointegration as the presence or absence of infrabony pocket formation and bone implant contact percentage. They found that although the contact percentage was comparable between the 2 groups, infrabony pocket formation was significantly more prevalent in the $60^{\circ} \mathrm{C}$ group. These results underline the importance of temperature control during implant site preparation. In the present thesis, we sought, first of all, to examine the effect of several factors that we believed would significantly contribute to heat generation during osteotomy: the presence of the metal sleeve in the surgical template and the combination of different drilling speed with different temperature irrigation fluids. The effect of metal to metal contact was compared with freehand osteotomy, and 3 further factors, sterilization, drilling speed, and drill wear, were also considered. To summarize the findings, at $800 \mathrm{rpm}$, the intraosseous temperature never reached the necrotic threshold in any of the examined conditions during the total of 210 osteotomies. At higher drilling speeds, 90 osteotomies could be safely (i.e., 
without approaching $47^{\circ} \mathrm{C}$ ) performed regardless of the applied sterilization protocol and whether the drilling was performed freehand or through a metal guide. The results also show that whether guide use led to a near-necrotic temperature increment depended largely on the applied sterilization protocol. In general, our hypothesis regarding the significant and cumulative effect of each studied factor during the experiments regarding the drill wear has been confirmed. It has been proven that the metal guide sleeve contributes significantly to heat generation during osteotomy, but this does not mean a safety risk if a soft sterilization protocol is used. It is important to mention that SMART Guide recommends a drilling speed of $800 \mathrm{rpm}$ in their protocols, which, in the light of our findings, seems to be a sound recommendation, especially that a single drill piece is not expected to be used anywhere near 210 times in real life. As for temperature elevations in guided osteotomy, only a few publications are currently available. Jeong et al compared a guided flapless technique with a flap procedure on resin models and found no significant difference (44). The study by Misir et al concluded that guided drilling led to mean peak temperature elevations more than $7^{\circ} \mathrm{C}$ higher than freehand osteotomy(45). However, their results are difficult to compare because of the use of bovine femora with a significantly thicker cortical layer. Migliorati et al performed their investigations on porcine ribs, and they found a higher mean peak temperature elevation with guided surgery $\left(4.81^{\circ} \mathrm{C}\right)$ than with the open flap technique $\left(4.21^{\circ} \mathrm{C}\right)(115)$. Both values are in the safe zone. Boa et al (37) compared external irrigation with no external irrigation using the guided technique and concluded that without cooling, harmful temperature elevations can develop, whereas external irrigation can efficiently control this problem. Dos Santos et al (75)applied the guided technique to rabbit tibiae and found no temperature elevation exceeding $5.8^{\circ} \mathrm{C}$, which is also within the safe zone. Our results suggest that the use of a low drilling speed of $800 \mathrm{rpm}$ combined with the external irrigation fluid being cooled to $10^{\circ} \mathrm{C}$ can result in a mean cortical intraosseous temperature change being below $1.0^{\circ} \mathrm{C}$, regardless of drill diameter or drilling method (freehand surgery or guided surgery). The use of irrigation fluid being cooled to $15^{\circ} \mathrm{C}$ provides no significant reduction of temperature change though All in all, the literature almost unequivocally suggests that guided osteotomy (with a metal sleeve) does not pose an extra safety risk in terms of temperature elevation, which is in agreement with our results. Naturally, this conclusion is true only if some factors are kept in check. Jochum et al (80) found that drills could be used more than 40 times before a significant temperature increment was detected. Misir and colleagues (45) reported temperature elevations of $4^{\circ} \mathrm{C}$ and $10^{\circ} \mathrm{C}$ after 35 and 45 osteotomies, respectively. In the study by Oliveira et al (72), 
involving 50 implant site preparations with stainless steel drills, no unsafe temperature increment was found. The investigation of Allsobrook et al (36) also led to the conclusion that drills are safe in terms of heat generation up to approximately 50 osteotomies. In their light microscopy study, Chacon et al (34) found very little drill wear after a series of 25 osteotomies. In the present study we found that at least 90 osteotomies could be performed in all studied conditions and that the most important limiting factor was drilling speed. Drill wear happened more rapidly at higher speeds, which led to greater temperature elevations earlier in the process. Speed control is an effective means of temperature control, and this is especially important in a guided, metal-on-metal setting. Harris et al (79) found that autoclaving might reduce cutting efficiency overtime. Our results support the contribution of sterilization to intraosseous heat generation during osteotomy, especially if osteotomy is performed through a surgical guide. It is safe to assume that an improper sterilization protocol (especially if applied repeatedly) contributes to drill wear by damaging the surface of the drill bit. What is a proper protocol might vary by the type and material of the drill bit, but we suggest that extended sessions of sterilization and rough mechanical cleaning are to be avoided with bits used for guided osteotomy. To summarize the above, the metal guide sleeve is an additional heat generating factor with a significant effect, still, it is safe if its effect is offset by proper speed setting and nondamaging sterilization/cleaning. Considering the rather high explanatory power of our model, it seems that the total number of osteotomies performed with a given drill bit, the speed of drilling and sterilization/cleaning are the most important factors to be controlled to prevent unsafe temperature elevation during guided osteotomy. This agrees with the literature. Finally, the results are to be interpreted with the following limitations in mind: first, this was an in vitro study. Even if we chose our model and based our procedures on the literature, these results come from a simplified experimental setting. Second, we applied fixed axial load. The obvious advantage is that this way we could avoid having to consider a factor that would have been difficult to measure. It must be seen, although that axial load is never fixed in real life. Another factor to be considered here is that we used 1 specific drill of 1 specific guided implantation system. This certainly limits the generalizability of the results to some extent. 
From the above, considering the aims and within the limitations of the research, the following conclusions are drawn:

The metal sleeve within the surgical guide is indeed a significant contributing factor to heat generation during guided osteotomy. Nonetheless, its effect can be offset by keeping the number of osteotomies performed with the same drill as low as possible, by drilling at lower speeds and by the application of soft sterilization/cleaning methods.

Low-speed drilling (800rpm) combined with $10^{\circ} \mathrm{C}$ irrigation fluid appears to be a safe method for implant site preparation and drilling through a guide. This way, guided osteotomy does not carry any safety risk as compared to freehand osteotomy.

Therefore, based on the results of the investigations that provide the basis of the present work, a low drilling speed with cooled irrigation are recommended when performing osteotomy through a surgical guide. $800 \mathrm{rpm}$ and $10^{\circ} \mathrm{C}$ proved to be optimal in our experiments. Furthermore, drills that are used for guided osteotomy should be taken care of with extra precaution regarding the cleaning and the sterilization protocols and their use (the drill bits) should be maximized at a level of 90 osteotomies. 


\section{Acknowledgements}

I would like to thank Professor József Piffkó, $\mathrm{MD}, \mathrm{DMD}, \mathrm{PhD}$ for his belief in me and my ability to complete this thesis and the support and knowledge which guided me over the last period of my career.

I would like to express my appreciation towards Kristof Boa, MD. His friendship, precision, positive mentality and calm temper has helped me through the obstacles encountered during our scientific work.

It is a great pleasure to acknowledge the support of Dr. Gábor Braunitzer, $\mathrm{PhD}$ who deserves a special place among those mentioned here for the ideas we share and for always being a source of great advice whenever I face difficulties in research.

The presented research would not have been possible to perform without the SMART Guide team. I would like to express my gratitude to Endre Varga Jr., DMD, PhD, Károly Bagi, and everyone else at dicomLAB Ltd. for their supporting our studies with both material and professional contributions.

This thesis would not have been possible without the background provided by my family. I would like to express my gratitude towards my parents, Éva Herczeg MD and Ahmad Barrak MD for their constant support throughout my whole life. A special thanks goes to my two lovely sisters: Sausan Barrak DMD and Nora Barrak DMD, who guide me in the field of dental medicine.

Finally, I would like to thank to a very special person in my life, my beautiful wife, Lilla Majzinger DMD who always supports my ideas whether they are good or bad and without her help this thesis would have remained a dream. 
1. Tahmaseb A, Wismeijer D, Coucke W, Derksen W. Computer technology applications in surgical implant dentistry: a systematic review. The International journal of oral \& maxillofacial implants. 2014;29 Suppl:25-42.

2. Jung RE, Schneider D, Ganeles J, Wismeijer D, Zwahlen M, Hammerle CH, et al. Computer technology applications in surgical implant dentistry: a systematic review. The International journal of oral \& maxillofacial implants. 2009;24 Suppl:92-109.

3. Branemark PI. Intravital microscopy. Its present status and its potentialities. Medical \& biological illustration. 1966;16(2):100-8.

4. Branemark PI. Osseointegration and its experimental background. The Journal of prosthetic dentistry. 1983;50(3):399-410.

5. Branemark PI, Hansson BO, Adell R, Breine U, Lindstrom J, Hallen O, et al. [Intraosseous implants]. Odontostomatologia E Implantoprotesi. 1980(1):24-5.

6. Branemark PI, Hansson BO, Adell R, Breine U, Lindstrom J, Hallen O, et al. Osseointegrated implants in the treatment of the edentulous jaw. Experience from a 10-year period. Scandinavian journal of plastic and reconstructive surgery Supplementum. 1977;16:1-132.

7. Branemark PI, Lindstrom J, Hallen O, Breine U, Jeppson PH, Ohman A. Reconstruction of the defective mandible. Scandinavian journal of plastic and reconstructive surgery. 1975;9(2):116-28.

8. Branemark PI, Breine U, Adell R, Hansson BO, Lindstrom J, Ohlsson A. [Experimental studies on intra-osseous anchorage of dental prosthesis]. Arsbok Goteborgs tandlakare-sallskap. 1970:9-25.

9. Branemark PI. [Rehabilitation with a denture anchored to the jawbone]. Lakartidningen. 1972;69(42):4813-4.

10. Branemark PI, Adell R, Hansson BO. [Reconstruction of jaws and intraosseous anchorage of dental prosthesis]. Tandlakartidningen. 1971;63(13):486-97.

11. Branemark PI, Adell R, Breine U, Hansson BO, Lindstrom J, Ohlsson A. Intraosseous anchorage of dental prostheses. I. Experimental studies. Scandinavian journal of plastic and reconstructive surgery. 1969;3(2):81-100.

12. Branemark PI. Vital microscopy of bone marrow in rabbit. Scandinavian journal of clinical and laboratory investigation. 1959;11 Supp 38:1-82. 
13. Mishra SK, Chowdhary R, Chrcanovic BR, Branemark PI. Osseoperception in Dental Implants: A Systematic Review. Journal of prosthodontics : official journal of the American College of Prosthodontists. 2016;25(3):185-95.

14. Mishra SK, Chowdhary R. Heat generated by dental implant drills during osteotomy-a review: heat generated by dental implant drills. Journal of Indian Prosthodontic Society. 2014;14(2):131-43.

15. Adell R, Lekholm U, Rockler B, Branemark PI. A 15-year study of osseointegrated implants in the treatment of the edentulous jaw. International journal of oral surgery. 1981;10(6):387-416.

16. Tehemar SH. Factors affecting heat generation during implant site preparation: a review of biologic observations and future considerations. The International journal of oral \& maxillofacial implants. 1999;14(1):127-36.

17. Marco F, Milena F, Gianluca G, Vittoria O. Peri-implant osteogenesis in health and osteoporosis. Micron. 2005;36(7-8):630-44.

18. Linder L. Osseointegration of metallic implants. I. Light microscopy in the rabbit. Acta orthopaedica Scandinavica. 1989;60(2):129-34.

19. Jakobsen T, Bechtold JE, Soballe K, Jensen T, Vestermark MT, Baas J. Local delivery of zoledronate from a poly (d,l-lactide)-coating increases fixation of hydroxycoated implants. Journal of orthopaedic research : official publication of the Orthopaedic Research Society. 2017;35(5):974-9.

20. Khan SN, Cammisa FP, Jr., Sandhu HS, Diwan AD, Girardi FP, Lane JM. The biology of bone grafting. The Journal of the American Academy of Orthopaedic Surgeons. 2005;13(1):77-86.

21. Eberhardt C, Habermann B, Muller S, Schwarz M, Bauss F, Kurth AH. The bisphosphonate ibandronate accelerates osseointegration of hydroxyapatite-coated cementless implants in an animal model. Journal of orthopaedic science : official journal of the Japanese Orthopaedic Association. 2007;12(1):61-6.

22. Watanabe F, Tawada Y, Komatsu S, Hata Y. Heat distribution in bone during preparation of implant sites: heat analysis by real-time thermography. The International journal of oral \& maxillofacial implants. 1992;7(2):212-9.

23. Eriksson A, Albrektsson T, Grane B, McQueen D. Thermal injury to bone. A vitalmicroscopic description of heat effects. International journal of oral surgery. 1982;11(2):115-21.

24. Eriksson RA, Albrektsson T. The effect of heat on bone regeneration: an experimental study in the rabbit using the bone growth chamber. Journal of oral and 
maxillofacial surgery : official journal of the American Association of Oral and Maxillofacial Surgeons. 1984;42(11):705-11.

25. Eriksson AR, Albrektsson T. Temperature threshold levels for heat-induced bone tissue injury: a vital-microscopic study in the rabbit. The Journal of prosthetic dentistry. 1983;50(1):101-7.

26. Mohlhenrich SC, Modabber A, Steiner T, Mitchell DA, Holzle F. Heat generation and drill wear during dental implant site preparation: systematic review. The British journal of oral \& maxillofacial surgery. 2015;53(8):679-89.

27. Sharawy M, Misch CE, Weller N, Tehemar S. Heat generation during implant drilling: the significance of motor speed. Journal of oral and maxillofacial surgery : official journal of the American Association of Oral and Maxillofacial Surgeons. 2002;60(10):1160-9.

28. Haider R, Watzek G, Plenk H. Effects of drill cooling and bone structure on IMZ implant fixation. The International journal of oral \& maxillofacial implants. 1993;8(1):8391.

29. Barrak I, Joob-Fancsaly A, Braunitzer G, Varga E, Jr., Boa K, Piffko J. Intraosseous Heat Generation During Osteotomy Performed Freehand and Through Template With an Integrated Metal Guide Sleeve: An In Vitro Study. Implant dentistry. 2018;27(3):342-50.

30. Barrak I, Joob-Fancsaly A, Varga E, Boa K, Piffko J. Effect of the Combination of Low-Speed Drilling and Cooled Irrigation Fluid on Intraosseous Heat Generation During Guided Surgical Implant Site Preparation: An In Vitro Study. Implant dentistry. 2017;26(4):541-6.

31. Boa K, Barrak I, Varga E, Jr., Joob-Fancsaly A, Varga E, Piffko J. Intraosseous generation of heat during guided surgical drilling: an ex vivo study of the effect of the temperature of the irrigating fluid. The British journal of oral \& maxillofacial surgery. 2016;54(8):904-8.

32. Yacker MJ, Klein M. The effect of irrigation on osteotomy depth and bur diameter. The International journal of oral \& maxillofacial implants. 1996;11(5):634-8.

33. Cordioli G, Majzoub Z. Heat generation during implant site preparation: an in vitro study. The International journal of oral \& maxillofacial implants. 1997;12(2):186-93.

34. Chacon GE, Bower DL, Larsen PE, McGlumphy EA, Beck FM. Heat production by 3 implant drill systems after repeated drilling and sterilization. Journal of oral and maxillofacial surgery : official journal of the American Association of Oral and Maxillofacial Surgeons. 2006;64(2):265-9. 
35. Brisman DL. The effect of speed, pressure, and time on bone temperature during the drilling of implant sites. The International journal of oral \& maxillofacial implants. 1996;11(1):35-7.

36. Allsobrook OF, Leichter J, Holborrow D, Swain M. Descriptive study of the longevity of dental implant surgery drills. Clinical implant dentistry and related research. 2011;13(3):244-54.

37. Boa K, Varga E, Jr., Pinter G, Csonka A, Gargyan I, Varga E. External cooling efficiently controls intraosseous temperature rise caused by drilling in a drilling guide system: an in vitro study. The British journal of oral \& maxillofacial surgery. 2015;53(10):963-7.

38. Carvalho AC, Queiroz TP, Okamoto R, Margonar R, Garcia IR, Jr., Magro Filho O. Evaluation of bone heating, immediate bone cell viability, and wear of high-resistance drills after the creation of implant osteotomies in rabbit tibias. The International journal of oral \& maxillofacial implants. 2011;26(6):1193-201.

39. Iyer S, Weiss C, Mehta A. Effects of drill speed on heat production and the rate and quality of bone formation in dental implant osteotomies. Part II: Relationship between drill speed and healing. The International journal of prosthodontics. 1997;10(6):536-40.

40. Iyer S, Weiss C, Mehta A. Effects of drill speed on heat production and the rate and quality of bone formation in dental implant osteotomies. Part I: Relationship between drill speed and heat production. The International journal of prosthodontics. 1997;10(5):411-4.

41. Strbac GD, Giannis K, Unger E, Mittlbock M, Watzek G, Zechner W. A novel standardized bone model for thermal evaluation of bone osteotomies with various irrigation methods. Clinical oral implants research. 2014;25(5):622-31.

42. Oh HJ, Wikesjo UM, Kang HS, Ku Y, Eom TG, Koo KT. Effect of implant drill characteristics on heat generation in osteotomy sites: a pilot study. Clinical oral implants research. 2011;22(7):722-6.

43. Gehrke SA, Bettach R, Taschieri S, Boukhris G, Corbella S, Del Fabbro M. Temperature Changes in Cortical Bone after Implant Site Preparation Using a Single Bur versus Multiple Drilling Steps: An In Vitro Investigation. Clinical implant dentistry and related research. 2015;17(4):700-7.

44. Jeong SM, Yoo JH, Fang Y, Choi BH, Son JS, Oh JH. The effect of guided flapless implant procedure on heat generation from implant drilling. Journal of cranio-maxillofacial surgery : official publication of the European Association for Cranio-Maxillo-Facial Surgery. 2014;42(6):725-9.

45. Misir AF, Sumer M, Yenisey M, Ergioglu E. Effect of surgical drill guide on heat generated from implant drilling. Journal of oral and maxillofacial surgery : official journal of the American Association of Oral and Maxillofacial Surgeons. 2009;67(12):2663-8. 
46. Markovic A, Misic T, Milicic B, Calvo-Guirado JL, Aleksic Z, Ethinic A. Heat generation during implant placement in low-density bone: effect of surgical technique, insertion torque and implant macro design. Clinical oral implants research. 2013;24(7):798805.

47. Sumer M, Misir AF, Telcioglu NT, Guler AU, Yenisey M. Comparison of heat generation during implant drilling using stainless steel and ceramic drills. Journal of oral and maxillofacial surgery : official journal of the American Association of Oral and Maxillofacial Surgeons. 2011;69(5):1350-4.

48. Bulloch SE, Olsen RG, Bulloch B. Comparison of heat generation between internally guided (cannulated) single drill and traditional sequential drilling with and without a drill guide for dental implants. The International journal of oral \& maxillofacial implants. 2012;27(6):1456-60.

49. Quaranta A, Andreana S, Spazzafumo L, Piemontese M. An in vitro evaluation of heat production during osteotomy preparation for dental implants with compressive osteotomes. Implant dentistry. 2013;22(2):161-4.

50. Misic T, Markovic A, Todorovic A, Colic S, Miodrag S, Milicic B. An in vitro study of temperature changes in type 4 bone during implant placement: bone condensing versus bone drilling. Oral surgery, oral medicine, oral pathology, oral radiology, and endodontics. 2011;112(1):28-33.

51. Wachter R, Stoll P. Increase of temperature during osteotomy. In vitro and in vivo investigations. International journal of oral and maxillofacial surgery. 1991;20(4):245-9.

52. Horch HH, Keiditsch E. [Morphological findings on the tissue lesion and bone regeneration after laser osteotomy]. Deutsche zahnarztliche Zeitschrift. 1980;35(1):22-4.

53. Scarano A, Piattelli A, Assenza B, Carinci F, Di Donato L, Romani GL, et al. Infrared thermographic evaluation of temperature modifications induced during implant site preparation with cylindrical versus conical drills. Clinical implant dentistry and related research. 2011;13(4):319-23.

54. Kim SJ, Yoo J, Kim YS, Shin SW. Temperature change in pig rib bone during implant site preparation by low-speed drilling. Journal of applied oral science : revista FOB. 2010;18(5):522-7.

55. Strbac GD, Unger E, Donner R, Bijak M, Watzek G, Zechner W. Thermal effects of a combined irrigation method during implant site drilling. A standardized in vitro study using a bovine rib model. Clinical oral implants research. 2014;25(6):665-74.

56. Strbac GD, Giannis K, Unger E, Mittlbock M, Vasak C, Watzek G, et al. Drillingand withdrawing-related thermal changes during implant site osteotomies. Clinical implant dentistry and related research. 2015;17(1):32-43. 
57. Augustin G, Davila S, Mihoci K, Udiljak T, Vedrina DS, Antabak A. Thermal osteonecrosis and bone drilling parameters revisited. Archives of orthopaedic and trauma surgery. 2008;128(1):71-7.

58. Jacobsson M, Albrektsson T, Turesson I. Dynamics of irradiation injury to bone tissue. A vital microscopic investigation. Acta radiologica Oncology. 1985;24(4):343-50.

59. Thompson HC. Effect of drilling into bone. J Oral Surg (Chic). 1958;16(1):22-30.

60. Pallan FG. Histological changes in bone after insertdon of skeletal fixation pins. Journal of oral surgery, anesthesia, and hospital dental service. 1960;18:400-8.

61. Matthews LS, Hirsch C. Temperatures measured in human cortical bone when drilling. The Journal of bone and joint surgery American volume. 1972;54(2):297-308.

62. Lavelle C, Wedgwood D. Effect of internal irrigation on frictional heat generated from bone drilling. Journal of oral surgery. 1980;38(7):499-503.

63. Eriksson RA, Adell R. Temperatures during drilling for the placement of implants using the osseointegration technique. Journal of oral and maxillofacial surgery : official journal of the American Association of Oral and Maxillofacial Surgeons. 1986;44(1):4-7.

64. Eriksson AR, Albrektsson T, Albrektsson B. Heat caused by drilling cortical bone. Temperature measured in vivo in patients and animals. Acta orthopaedica Scandinavica. 1984;55(6):629-31.

65. Abouzgia MB, James DF. Temperature rise during drilling through bone. The International journal of oral \& maxillofacial implants. 1997;12(3):342-53.

66. Bachus KN, Rondina MT, Hutchinson DT. The effects of drilling force on cortical temperatures and their duration: an in vitro study. Medical engineering \& physics. 2000;22(10):685-91.

67. Hobkirk JA, Rusiniak K. Investigation of variable factors in drilling bone. Journal of oral surgery. 1977;35(12):968-73.

68. Rashad A, Kaiser A, Prochnow N, Schmitz I, Hoffmann E, Maurer P. Heat production during different ultrasonic and conventional osteotomy preparations for dental implants. Clinical oral implants research. 2011;22(12):1361-5.

69. Stelzle F, Frenkel C, Riemann M, Knipfer C, Stockmann P, Nkenke E. The effect of load on heat production, thermal effects and expenditure of time during implant site preparation - an experimental ex vivo comparison between piezosurgery and conventional drilling. Clinical oral implants research. 2014;25(2):e140-8. 
70. Ercoli C, Funkenbusch PD, Lee HJ, Moss ME, Graser GN. The influence of drill wear on cutting efficiency and heat production during osteotomy preparation for dental implants: a study of drill durability. The International journal of oral \& maxillofacial implants. 2004;19(3):335-49.

71. Scarano A, Carinci F, Quaranta A, Di Iorio D, Assenza B, Piattelli A. Effects of bur wear during implant site preparation: an in vitro study. International journal of immunopathology and pharmacology. 2007;20(1 Suppl 1):23-6.

72. Oliveira N, Alaejos-Algarra F, Mareque-Bueno J, Ferres-Padro E, HernandezAlfaro F. Thermal changes and drill wear in bovine bone during implant site preparation. A comparative in vitro study: twisted stainless steel and ceramic drills. Clinical oral implants research. 2012;23(8):963-9.

73. Queiroz TP, Souza FA, Okamoto R, Margonar R, Pereira-Filho VA, Garcia Junior IR, et al. Evaluation of immediate bone-cell viability and of drill wear after implant osteotomies: immunohistochemistry and scanning electron microscopy analysis. Journal of oral and maxillofacial surgery : official journal of the American Association of Oral and Maxillofacial Surgeons. 2008;66(6):1233-40.

74. dos Santos PL, Queiroz TP, Margonar R, Gomes de Souza Carvalho AC, Okamoto R, de Souza Faloni AP, et al. Guided implant surgery: what is the influence of this new technique on bone cell viability? Journal of oral and maxillofacial surgery : official journal of the American Association of Oral and Maxillofacial Surgeons. 2013;71(3):505-12.

75. dos Santos PL, Queiroz TP, Margonar R, de Souza Carvalho AC, Betoni W, Jr., Rezende RR, et al. Evaluation of bone heating, drill deformation, and drill roughness after implant osteotomy: guided surgery and classic drilling procedure. The International journal of oral \& maxillofacial implants. 2014;29(1):51-8.

76. Pires LF, Tandler B, Bissada N, Duarte S, Jr. Comparison of heat generated by alumina-toughened zirconia and stainless steel burs for implant placement. The International journal of oral \& maxillofacial implants. 2012;27(5):1023-8.

77. Margonar R, Queiroz TP, Luvizuto ER, Santos PL, Wady AF, Paleari AG. Anterior tooth rehabilitation with frozen homogenous bone graft and immediately loaded titanium implant using computer-guided surgery. The Journal of craniofacial surgery. 2012;23(5):e470-2.

78. Allan W, Williams ED, Kerawala CJ. Effects of repeated drill use on temperature of bone during preparation for osteosynthesis self-tapping screws. The British journal of oral \& maxillofacial surgery. 2005;43(4):314-9.

79. Harris BH, Kohles SS. Effects of mechanical and thermal fatigue on dental drill performance. The International journal of oral \& maxillofacial implants. 2001;16(6):81926. 
80. Jochum RM, Reichart PA. Influence of multiple use of Timedur-titanium cannon drills: thermal response and scanning electron microscopic findings. Clinical oral implants research. 2000;11(2):139-43.

81. Karaca F, Aksakal B, Kom M. Influence of orthopaedic drilling parameters on temperature and histopathology of bovine tibia: an in vitro study. Medical engineering \& physics. 2011;33(10):1221-7.

82. Pandey RK, Panda SS. Drilling of bone: A comprehensive review. Journal of clinical orthopaedics and trauma. 2013;4(1):15-30.

83. Augustin G, Zigman T, Davila S, Udilljak T, Staroveski T, Brezak D, et al. Cortical bone drilling and thermal osteonecrosis. Clinical biomechanics. 2012;27(4):313-25.

84. Sener BC, Dergin G, Gursoy B, Kelesoglu E, Slih I. Effects of irrigation temperature on heat control in vitro at different drilling depths. Clinical oral implants research. 2009;20(3):294-8.

85. Benington IC, Biagioni PA, Briggs J, Sheridan S, Lamey PJ. Thermal changes observed at implant sites during internal and external irrigation. Clinical oral implants research. 2002;13(3):293-7.

86. Lekholm U. Clinical procedures for treatment with osseointegrated dental implants. The Journal of prosthetic dentistry. 1983;50(1):116-20.

87. Huiskes R. Some fundamental aspects of human joint replacement. Analyses of stresses and heat conduction in bone-prosthesis structures. Acta orthopaedica Scandinavica Supplementum. 1980;185:1-208.

88. Kirschner H, Meyer W. [Development of an internal cooling mechanism for surgical drills]. Deutsche zahnarztliche Zeitschrift. 1975;30(7):436-8.

89. Seeger P, Tetsch P. [Animal experimental studies on the regeneration of controlled bone lesions in varying cooling preceedures]. Deutsche zahnarztliche Zeitschrift. 1978;33(12):870-2.

90. Schmitt W, Weber HJ, Jahn D. [Thermic studies during drilling in compact bone with different cooling systems]. Deutsche zahnarztliche Zeitschrift. 1988;43(7):802-5.

91. Kirschner H, Bolz U, Michel G. [Thermometric studies using internally cooled and uncooled burs on the jaws and teeth]. Deutsche zahnarztliche Zeitschrift. 1984;39(1):30-2.

92. Hammerle CH, Stone P, Jung RE, Kapos T, Brodala N. Consensus statements and recommended clinical procedures regarding computer-assisted implant dentistry. The International journal of oral \& maxillofacial implants. 2009;24 Suppl:126-31. 
93. Hammerle CH, Cordaro L, van Assche N, Benic GI, Bornstein M, Gamper F, et al. Digital technologies to support planning, treatment, and fabrication processes and outcome assessments in implant dentistry. Summary and consensus statements. The 4th EAO consensus conference 2015. Clinical oral implants research. 2015;26 Suppl 11:97-101.

94. Loubele M, Maes F, Schutyser F, Marchal G, Jacobs R, Suetens P. Assessment of bone segmentation quality of cone-beam CT versus multislice spiral CT: a pilot study. Oral surgery, oral medicine, oral pathology, oral radiology, and endodontics. 2006;102(2):22534.

95. Loubele M, Jacobs R, Maes F, Schutyser F, Debaveye D, Bogaerts R, et al. Radiation dose vs. image quality for low-dose CT protocols of the head for maxillofacial surgery and oral implant planning. Radiation protection dosimetry. 2005;117(1-3):211-6.

96. Loubele M, Bogaerts R, Van Dijck E, Pauwels R, Vanheusden S, Suetens P, et al. Comparison between effective radiation dose of CBCT and MSCT scanners for dentomaxillofacial applications. European journal of radiology. 2009;71(3):461-8.

97. Guerrero ME, Jacobs R, Loubele M, Schutyser F, Suetens P, van Steenberghe D. State-of-the-art on cone beam CT imaging for preoperative planning of implant placement. Clinical oral investigations. 2006;10(1):1-7.

98. Widmann G, Stoffner R, Schullian P, Widmann R, Keiler M, Zangerl A, et al. Comparison of the accuracy of invasive and noninvasive registration methods for imageguided oral implant surgery. The International journal of oral \& maxillofacial implants. 2010;25(3):491-8.

99. Ersoy AE, Turkyilmaz I, Ozan O, McGlumphy EA. Reliability of implant placement with stereolithographic surgical guides generated from computed tomography: clinical data from 94 implants. Journal of periodontology. 2008;79(8):1339-45.

100. Di Giacomo GA, da Silva JV, da Silva AM, Paschoal GH, Cury PR, Szarf G. Accuracy and complications of computer-designed selective laser sintering surgical guides for flapless dental implant placement and immediate definitive prosthesis installation. Journal of periodontology. 2012;83(4):410-9.

101. Di Giacomo GA, Cury PR, de Araujo NS, Sendyk WR, Sendyk CL. Clinical application of stereolithographic surgical guides for implant placement: preliminary results. Journal of periodontology. 2005;76(4):503-7.

102. Di Giacomo GA, Cury PR, da Silva AM, da Silva JV, Ajzen SA. A selective laser sintering prototype guide used to fabricate immediate interim fixed complete arch prostheses in flapless dental implant surgery: Technique description and clinical results. The Journal of prosthetic dentistry. 2016;116(6):874-9. 
103. Pettersson A, Komiyama A, Hultin M, Nasstrom K, Klinge B. Accuracy of virtually planned and template guided implant surgery on edentate patients. Clinical implant dentistry and related research. 2012;14(4):527-37.

104. Pettersson A, Kero T, Soderberg R, Nasstrom K. Accuracy of virtually planned and CAD/CAM-guided implant surgery on plastic models. The Journal of prosthetic dentistry. 2014;112(6):1472-8.

105. Pettersson A, Kero T, Gillot L, Cannas B, Faldt J, Soderberg R, et al. Accuracy of CAD/CAM-guided surgical template implant surgery on human cadavers: Part I. The Journal of prosthetic dentistry. 2010;103(6):334-42.

106. Tahmaseb A, van de Weijden JJ, Mercelis P, De Clerck R, Wismeijer D. Parameters of passive fit using a new technique to mill implant-supported superstructures: an in vitro study of a novel three-dimensional force measurement-misfit method. The International journal of oral \& maxillofacial implants. 2010;25(2):247-57.

107. Tahmaseb A, De Clerck R, Eckert S, Wismeijer D. Reference-based digital concept to restore partially edentulous patients following an immediate loading protocol: a pilot study. The International journal of oral \& maxillofacial implants. 2011;26(4):707-17.

108. Tahmaseb A, De Clerck R, Aartman I, Wismeijer D. Digital protocol for referencebased guided surgery and immediate loading: a prospective clinical study. The International journal of oral \& maxillofacial implants. 2012;27(5):1258-70.

109. Davidson SR, James DF. Measurement of thermal conductivity of bovine cortical bone. Medical engineering \& physics. 2000;22(10):741-7.

110. Katranji A, Misch K, Wang HL. Cortical bone thickness in dentate and edentulous human cadavers. Journal of periodontology. 2007;78(5):874-8.

111. Augustin G, Davila S, Udiljak T, Vedrina DS, Bagatin D. Determination of spatial distribution of increase in bone temperature during drilling by infrared thermography: preliminary report. Archives of orthopaedic and trauma surgery. 2009;129(5):703-9.

112. Sedlin ED, Hirsch C. Factors affecting the determination of the physical properties of femoral cortical bone. Acta orthopaedica Scandinavica. 1966;37(1):29-48.

113. Rouiller C, Majno G. [Morphological and chemical studies of bones after the application of heat]. Beitrage zur pathologischen Anatomie und zur allgemeinen Pathologie. 1953;113(1):100-20.

114. Trisi P, Berardini M, Falco A, Podaliri Vulpiani M, Perfetti G. Insufficient irrigation induces peri-implant bone resorption: an in vivo histologic analysis in sheep. Clinical oral implants research. 2014;25(6):696-701. 
115. Migliorati M, Amorfini L, Signori A, Barberis F, Silvestrini Biavati A, Benedicenti S. Internal bone temperature change during guided surgery preparations for dental implants: an in vitro study. The International journal of oral \& maxillofacial implants. 2013;28(6):1464-9. 
Appendix: Copies of the publications that provide the basis of the thesis 
Publication No. I 


\section{Publication No. II.}

